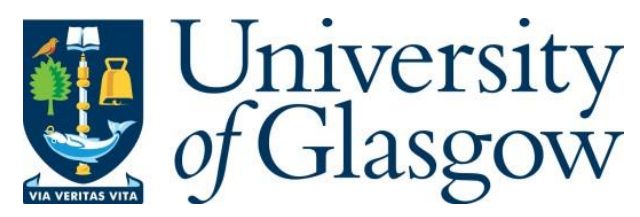

Zheng, X.-J., Bell, N. L., Stevens, C. J., Zhong, Y.-X., Schreckenbach, G., Arnold, P. L., Love, J. B. and Pan, Q.-J. (2016) Relativistic DFT and experimental studies of monoand bis-actinyl complexes of an expanded Schiff-base polypyrrole macrocycle. Dalton Transactions, 45(40), pp. 15910-15921.

There may be differences between this version and the published version. You are advised to consult the publisher's version if you wish to cite from it.

http://eprints.gla.ac.uk/215195/

Deposited on: 12 May 2020

Enlighten - Research publications by members of the University of Glasgow http://eprints.gla.ac.uk 


\title{
Relativistic DFT and Experimental Studies of Mono- and Bis-Actinyl Complexes of an Expanded Schiff-Base Polypyrrole Macrocycle
}

\author{
Xiu-Jun Zheng, ${ }^{[a]}$ Nicola L. Bell,,${ }^{[c]}$ Charlotte J. Stevens, ${ }^{[c]}$ Yu-Xi Zhong, ${ }^{[a]}$ Georg Schreckenbach, ${ }^{[b]}$ \\ Polly L. Arnold, ${ }^{*[c]}$ Jason B. Love*[c] and Qing-Jiang Pan*[a] \\ ${ }^{[a]}$ Key Laboratory of Functional Inorganic Material Chemistry of Education Ministry, School of Chemistry and \\ Materials Science, Heilongjiang University, Harbin 150080, China \\ ${ }^{[b]}$ Department of Chemistry, University of Manitoba, Winnipeg, MB, Canada, R3T 2N2 \\ ${ }^{[c]}$ EaStCHEM School of Chemistry, University of Edinburgh, Edinburgh, UK, EH9 3FJ \\ *Corresponding authors: \\ panqiitc@163.com (QJ Pan); jason.love@ed.ac.uk (JB Love); polly.arnold@ed.ac.uk (PL Arnold)
}

\begin{abstract}
The computationally- and experimentally-determined molecular structures of a bis-uranyl(VI) complex of an expanded Schiff-base polypyrrolic macrocycle $\left[\left(\mathrm{UO}_{2}\right)_{2}(\mathrm{~L})\right]$ are in close agreement only if the pyridine in the fifth equatorial donor site on the uranium is included in the calculations. The relativistic density functional theory (DFT) calculations presented here are augmented from those on previously reported simpler frameworks, and demonstrate that other augmentations, such as the incorporation of condensed-phase media and the changes in the peripheral groups of the ligand, have only a slight effect. Synthetic routes to pure samples of the bis- and mono-uranyl(VI) complexes have been developed using pyridine and arene solvents, respectively, allowing the experimental determination of the molecular structures by
\end{abstract}


X-ray single crystal diffraction; these agree well with the calculated structures. A comprehensive set of calculations have been performed on a series of actinyl $\mathrm{AnO}_{2}{ }^{\mathrm{n}+}$ complexes of this macrocyclic ligand. These include both bis- and mono-actinyl adducts for the metals $\mathrm{U}, \mathrm{Np}$ and $\mathrm{Pu}$, and formal oxidation states $\mathrm{VI}$ and $\mathrm{V}$. The reduction potentials of the complexes for $\mathrm{U}, \mathrm{Np}$, and $\mathrm{Pu}$, incorporating both solvation and spin-orbit coupling considerations, show the order $\mathrm{Np}>\mathrm{Pu}>\mathrm{U}$. The agreement between experimental and computed data for $U$ is excellent. A particularly unusual structure of the mononuclear plutonyl(V) complex was predicted by quantum chemical calculations, in which a twist in the macrocycle allows one of the two endo-oxo groups to form a hydrogen bond to one pyrrole group of the opposite side of the macrocycle, in accordance with this member of the set containing the most Lewis basic oxo groups. The calculated and measured electrochemical potentials for $U$ are particularly close, suggesting that at this level of computation predictions made about the significantly more radiotoxic $\mathrm{Np}$ and $\mathrm{Pu}$ molecules should be accurate.

Keywords: actinyl complexes of polypyrrolic macrocycle; relativistic DFT; redox potential; crystal structure; cyclic voltametry

\section{Introduction}

The use of actinides for nuclear power, nuclear weapons production and medicine has led to growing concerns about waste management and potential environmental impact. $^{1-6}$ In the processing of nuclear fuel and spent nuclear fuel, ${ }^{1,2}$ the U(VI) uranyl ion $\left(\mathrm{UO}_{2}{ }^{2+}\right)$ is the most prevalent species due to its extraordinarily chemically robust axial $\mathrm{U}=\mathrm{O}$ bonds. ${ }^{7-9}$ Its $\mathrm{U}(\mathrm{V})$ analogue readily disproportionates into $\mathrm{U}(\mathrm{IV})$ uranium species and $\mathrm{U}(\mathrm{VI}) \mathrm{UO}_{2}{ }^{2+}$ in an aqueous environment. ${ }^{8,} 9$ In contrast, the $\mathrm{An}(\mathrm{V})$ transuranium actinyl ions $\mathrm{NpO}_{2}{ }^{+}$and $\mathrm{PuO}_{2}{ }^{+}$are stable and relatively mobile in the environment. ${ }^{3-5}$ In addition, the common Pu(VI) actinyl complexes are highly soluble 
and mobile in water. ${ }^{2-4}$ The safe immobilization of radionuclides and elimination of environmental contamination of nuclear waste requires an in-depth understand of the structures, reaction behavior and redox property of uranium and transuranium complexes.
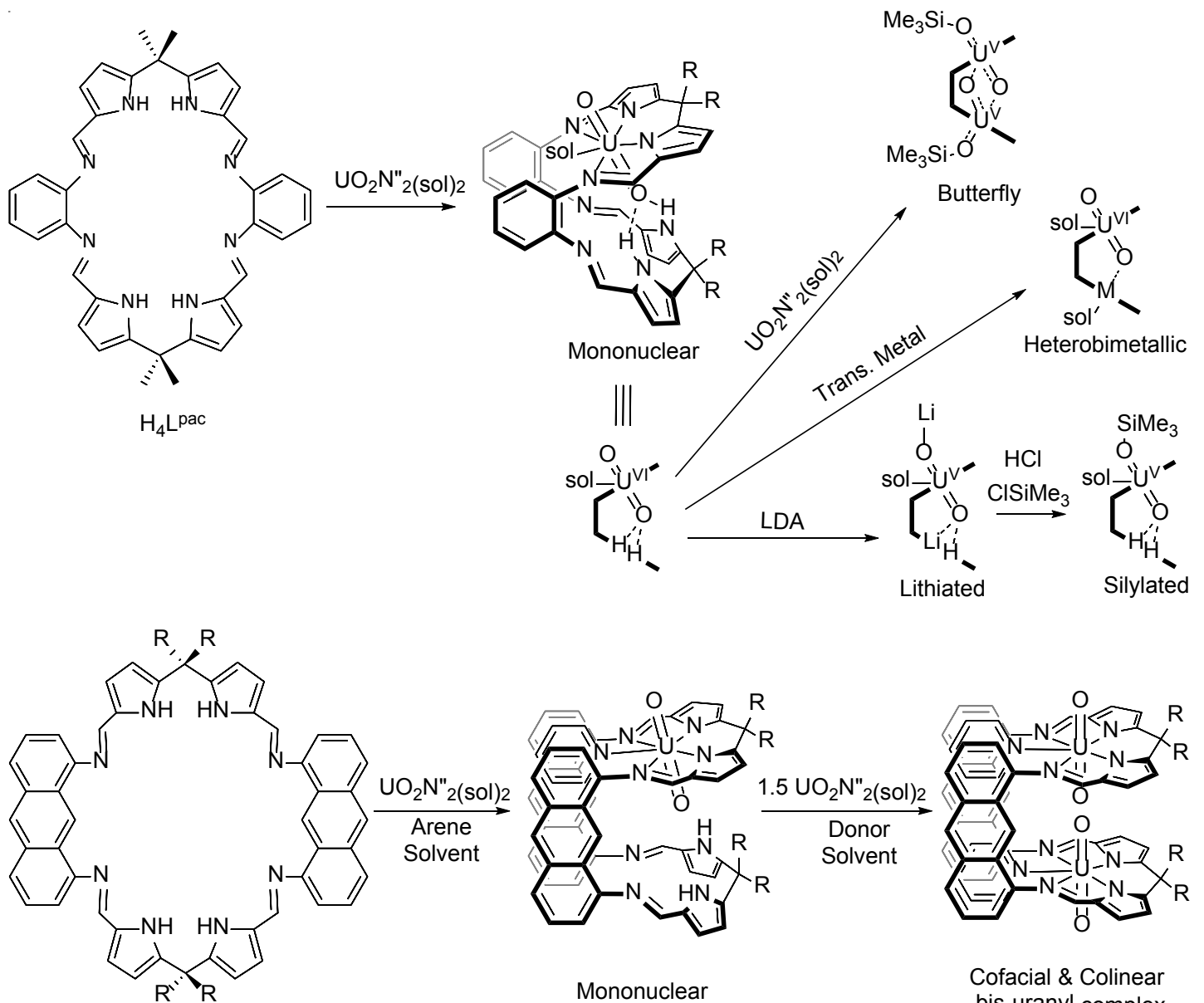

$\mathrm{H}_{4} \mathrm{~L} \mathrm{H}_{4} \mathrm{~L}, \mathrm{R}=\mathrm{Me}$ (Calc.)

$\mathrm{H}_{4} \mathrm{~L}^{\prime} \mathrm{H}_{4} \mathrm{~L} \cdot \mathrm{R}=\mathrm{Et}$ (Expt.)

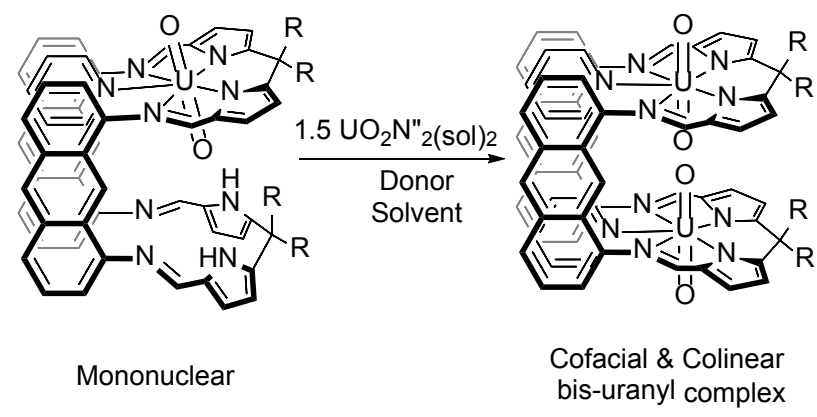

Chart 1. Mono- and binuclear uranyl complexes of polypyrrolic macrocycles. $\mathrm{H}_{4} \mathrm{~L}$, terminated by methyl groups, was used in most calculations, compared to the experimental ligand $\mathrm{H}_{4} \mathrm{~L}^{\prime}$ with ethyl substituents, see the text.

A variety of ancillary ions and molecules such as halides, tetrahydrofuran (THF), pyridine, porphyrin and polypyrroles have been used to explore the equatorial complexation chemistry of actinyl ions under mild conditions. ${ }^{10-33}$ The flexible Schiff-base polypyrrolic macrocycle $\left(\mathrm{H}_{4} \mathrm{~L}^{\text {pac }}\right.$ in Chart 1) was first prepared independently by the groups of Sessler ${ }^{34}$ and Love. ${ }^{35}$ Using uranyl silylamide starting 
materials, Arnold and Love and co-workers synthesised "Pacman"-shaped complexes $\left[(\mathrm{sol})\left(\mathrm{U}^{\mathrm{VI}} \mathrm{O}_{2}\right)\left(\mathrm{H}_{2} \mathrm{~L}^{\mathrm{pac}}\right)\right]$ (sol = pyridine and THF). ${ }^{36}$ The normal bis-uranyl(VI) complex was not obtainable, restricted by the lack of space in the ligand and the robust linear trans-uranyl(VI) ion. This has been evidenced by the synthesised complexes, heterobimetallic $\left[(\mathrm{THF})\left(\mathrm{OU}^{\mathrm{VI}} \mathrm{O} \cdots \mathrm{M}^{\mathrm{II}}\right)(\mathrm{THF})\left(\mathrm{L}^{\mathrm{pac}}\right)\right](\mathrm{M}=\mathrm{Mn}, \mathrm{Fe}$ and $\mathrm{Co})^{31}$ (the remaining small space within the Pacman cleft is suitable for a transition metal ion) and butterfly-shaped $\left[\left(\left(\mathrm{Me}_{3} \mathrm{Si}\right) \mathrm{OU}^{\mathrm{V}}(\mu-\mathrm{O})\right)_{2}\left(\mathrm{~L}^{\mathrm{pac}}\right)\right]^{37}$ in which one trans-oxo-group has migrated to a cis-position as the linear 'yl' bonding has presumably been weakened upon reduction to $\mathrm{U}^{\mathrm{V}}$. These complexes are shown schematically in Chart 1. Recently, a binuclear uranyl(VI) complex that contains two linear uranyl ions has been accessed using the expanded Schiff-base polypyrrolic macrocycle $\mathrm{H}_{4} \mathrm{~L}^{\prime}$ in Chart $1 .{ }^{38}$ However, the synthetic route provided a mixture of mono- and bis-uranyl(VI) complexes with separation only possible by selective crystallization. Additionally, these polypyrrolic macrocyclic ligands are able to form complexes with a wide range of metals including $\mathrm{Cr}, \mathrm{Pd}, \mathrm{Zn}, \mathrm{Sn}, \mathrm{U}$ and $\mathrm{Ca}$, which would help improving actinide separation in the environment and further design more effective separation ligands.

Theoretical predictions on structures and reactions of the computed uranyl complexes of $\mathrm{H}_{4} \mathrm{~L}^{\text {pac }}$ and $\mathrm{H}_{4} \mathrm{~L}$ provided significant support for the experimental results. ${ }^{39-41}$ Additionally, these calculations, ${ }^{39,}{ }^{40}$ predicted the new butterfly-like geometry for $\mathrm{U}^{\mathrm{VI}}{ }_{2} \mathrm{O}_{4}$ in $\left[\left(\mathrm{OU}^{\mathrm{VI}}(\mu-\mathrm{O})\right)_{2}\left(\mathrm{~L}^{\mathrm{pac}}\right)\right]$ - a different type of cation-cation interaction $(\mathrm{CCI})^{32,42-55}$ to that observed so far (a $\mathrm{CCI}$ is defined when one actinyl metal centre is coordinated by the oxo atom of a second actinyl). Here, the occupation by one oxo of a mutually cis-coordination site was explained, since a much higher energetic barrier arises from the repulsion of the second uranyl entering into the small empty pocket of $\left[(\mathrm{THF})\left(\mathrm{U}^{\mathrm{VI}} \mathrm{O}_{2}\right)\left(\mathrm{H}_{2} \mathrm{~L}^{\mathrm{pac}}\right)\right]$, as lower than the barrier to oxo migration from trans to cis-uranyl position. This also helped to rationalise the experimental unavailability of the simple bis- $\left(\mathrm{U}^{\mathrm{VI}} \mathrm{O}_{2}\right)$ adduct of $\mathrm{H}_{4} \mathrm{~L}^{\text {pac }}$. On the other hand, in our previous communication, ${ }^{41}$ the binuclear uranyl complex of the anthracenyl 
diamido-based $\mathrm{H}_{4} \mathrm{~L}$ was predicted to be stable. The theoretical structure possesses a similar molecular skeleton to the subsequent solid state structure which contains two co-linear $\mathrm{UO}_{2}$ groups $5.11 \AA$ apart, as determined by X-ray crystal diffraction. ${ }^{38}$ However, it still differs in the relative arrangement of the two uranyl ions.

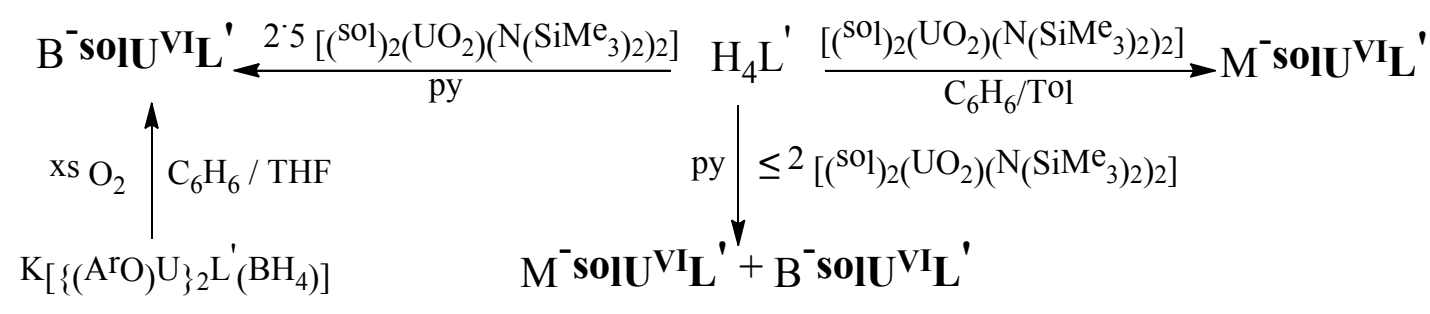

Chart 2. Synthetic routes to $\mathbf{M}-$ solU $^{\mathrm{VI}} \mathbf{L}^{\prime}$ and B-solU ${ }^{\mathrm{VI}} \mathbf{L}^{\prime}$ (sol = py and THF).

To elucidate the above structural discrepancy between experiment and theory as well as to gain further insight into the chemistry of the actinides, a series of monoand bis-actinyl complexes of the $\mathrm{H}_{4} \mathrm{~L}$ ligand have been systematically examined using scalar relativistic density functional theory (DFT). Geometries, electronic structures and properties of single-electron reduction reactions from $+\mathrm{VI}$ to $+\mathrm{V}$ oxidation state were addressed for $\mathrm{U}, \mathrm{Np}$, and Pu. Concurrently, the synthetic route (Chart 2) has been developed for the isolation of mononuclear $\left[(\mathrm{sol})\left(\mathrm{U}^{\mathrm{VI}} \mathrm{O}_{2}\right)\left(\mathrm{H}_{2} \mathrm{~L}^{\prime}\right)\right]$ and binuclear $\left[(\mathrm{sol})_{2}\left(\mathrm{U}^{\mathrm{VI}} \mathrm{O}_{2}\right)_{2}\left(\mathrm{~L}^{\prime}\right)\right]$ (sol = pyridine and $\left.\mathrm{THF}\right)$, enabling $\mathrm{X}$-ray structural and electrochemical characterization to be carried out and compared with the predictions made by computations.

\section{Scope and Theoretical/Experimental Procedures}

\subsection{Scope of the current study}

The pyridine-solvated complexes, including binuclear $\left[(p y)_{2}\left(\mathrm{An}^{\mathrm{m}} \mathrm{O}_{2}\right)_{2}(\mathrm{~L})\right]^{2 \mathrm{n}-4}$ and mononuclear $\left[(p y)\left(\mathrm{An}^{\mathrm{m}} \mathrm{O}_{2}\right)\left(\mathrm{H}_{2} \mathrm{~L}\right)\right]^{\mathrm{n}-2}(\mathrm{~m}=\mathrm{VI}, \mathrm{n}=2 ; \mathrm{m}=\mathrm{V}, \mathrm{n}=1 ; \mathrm{An}=\mathrm{U}, \mathrm{Np}$ and $\mathrm{Pu})$, were structurally optimised. These complexes are labeled as B-pyAn ${ }^{\mathbf{m}}$ and M-pyAn ${ }^{\mathbf{m}}$, respectively, compared with the pyridine-free complexes B-An ${ }^{\mathbf{m}}$ and $\mathbf{M}-\mathbf{A} \mathbf{n}^{\mathbf{m}}{ }^{41}$ Table $\mathrm{S} 1$ of Supporting Information. A mixed-valent complex $\left[(\mathrm{py})_{2}\left(\mathrm{U}^{\mathrm{VI}} \mathrm{O}_{2}\right)\left(\mathrm{U}^{\mathrm{V}} \mathrm{O}_{2}\right)(\mathrm{L})\right]^{-}$ 
(B-py $\mathbf{U}^{\mathbf{V I}-\mathbf{v}}$ ) was investigated for comparison.

The $\mathrm{H}_{4} \mathrm{~L}^{\prime}$ ligand with ethyl meso-substituents was used for the experimental studies, while its methyl meso-substituted analogue $\mathrm{H}_{4} \mathrm{~L}$ was employed to save computational cost (Chart 1). To examine the effect of this ligand simplification, [(py) $\left.\left(\mathrm{U}^{\mathrm{VI}} \mathrm{O}_{2}\right)\left(\mathrm{H}_{2} \mathrm{~L}^{\prime}\right)\right]$ $\left(\mathrm{M}-\mathbf{p y} \mathbf{U}^{\mathrm{VI}} \mathbf{L}^{\prime}\right)$ and $\left[(\text { py })_{2}\left(\mathrm{U}^{\mathrm{VI}} \mathrm{O}_{2}\right)_{2}\left(\mathrm{~L}^{\prime}\right)\right]\left(\mathrm{B}-\mathbf{p y} \mathbf{U}^{\mathrm{VI}} \mathbf{L}^{\prime}\right)$ were optimised and compared with the experimentally synthesised ones. Calculations on the THF-solvated complexes, $\left[(\mathrm{THF})\left(\mathrm{U}^{\mathrm{m}} \mathrm{O}_{2}\right)\left(\mathrm{H}_{2} \mathrm{~L}\right)\right]^{\mathrm{n}-2}\left(\mathrm{M}-T H F U^{\mathrm{m}} ; \mathrm{m}=\mathrm{VI}, \mathrm{n}=2 ; \mathrm{m}=\mathrm{V}, \mathrm{n}=1\right)$ and $\left[(\mathrm{THF})\left(\mathrm{U}^{\mathrm{VI}} \mathrm{O}_{2}\right)\left(\mathrm{H}_{2} \mathrm{~L}^{\prime}\right)\right]\left(\mathrm{M}-\mathbf{T H F U} \mathbf{V}^{\mathrm{VI}} \mathbf{L}^{\prime}\right)$, allow us to understand the solvent effects (Table S2).

In this work, we have also developed a new synthetic route (Chart 2) to cleanly

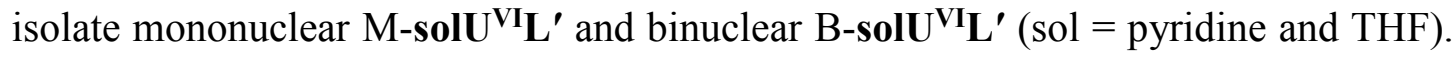
The four complexes have been structurally characterised using single crystal X-ray diffraction and their redox properties characterised by cyclic voltammetry experiments.

\subsection{Computational details}

Geometry structures of all complexes were fully optimised in the gas phase without symmetry constraints using the Priroda code. ${ }^{56-60}$ A scalar relativistic all-electron (AE) approach was applied ${ }^{61}$ with spin-orbit projected out and neglected from the full Dirac equation. $^{62}$ We used GGA DFT with the PBE functional ${ }^{63}$ in the calculations. All-electron correlation-consistent double- $\varsigma$ polarised quality basis sets (labeled as B-I) were employed for the large component, accompanied by the corresponding kinetically balanced basis sets for the small component and the respective auxiliary (fit) basis sets. ${ }^{58,59}$ The minimum nature of all the optimised structures was confirmed by analytical frequency calculations. Building on these, the thermodynamic data of the complexes were obtained. Population-based Mayer ${ }^{64}$ bond orders were calculated simultaneously.

With the ADF 2010.02 code,${ }^{65-67}$ we have calculated the solvation energy of each complex. An integration parameter of 6.0 was applied, unless otherwise noted. The 
solvent effect of pyridine was taken into account with the Conductor-Like Screening Model, COSMO ${ }^{68,69}$ The Klamt radii were used for the main group atoms $(\mathrm{H}=1.30$ $\AA, \mathrm{C}=2.00 \AA, \mathrm{N}=1.83 \AA$ and $\mathrm{O}=1.72 \AA)^{70}$ and for the actinide atoms (U, Np and $\mathrm{Pu}=1.70 \AA)^{39,40,71,72}$. The scalar relativistic ZORA method ${ }^{73-76}$ and Slater-type TZP basis sets (labeled as B-II) were used. With the small-core ZORA, the core orbitals $1 s-4 f$ for $\mathrm{U}, \mathrm{Np}$ and $\mathrm{Pu}$, and $1 s$ for $\mathrm{C}, \mathrm{N}$ and $\mathrm{O}$ were frozen. Additionally, effects of the condensed medium surrounding the real experimental complexes were simulated by the self-consistent reaction field while employing the COSMO model. Thus, both B-pyU $\mathbf{U}^{\mathbf{V I}}$ and B-U $\mathbf{U}^{\mathbf{V I}}$ were optimised in pyridine solution at the ADF: PBE/B-II/ZORA/COSMO level and in the gas phase at the ADF: PBE/B-II/ZORA/gas level (see Table S3).

\subsection{Experimental Details}

General information about synthetic techniques, NMR spectroscopy, cyclic voltammograms, and X-ray crystallographic data is described in Supporting Information. Syntheses and analytical data for the complexes shown in Chart 2 are as follows.

M-py $\mathbf{U}^{\mathbf{V I}} \mathbf{L}^{\prime}$. Toluene (ca. $20 \mathrm{~mL}$ ) was added to a mixture of $\mathrm{H}_{4} \mathrm{~L}^{\prime}(1.00 \mathrm{~g}, 1.23$ mmol, 1 eq.) and $\left[\left(\mathrm{py}_{2}\left(\mathrm{UO}_{2}\right)\left(\mathrm{N}\left(\mathrm{SiMe}_{3}\right)_{2}\right)_{2}\right](918 \mathrm{mg}, 1.23 \mathrm{mmol}, 1\right.$ eq. $)$ and the resulting brown solution stirred for 1 week. The time required to reach full conversion is dependent upon concentration taking up to 4 days at ca. $10 \mathrm{mmol} \mathrm{L}^{-1}$ and under $1 \mathrm{~h}$ at ca. $50 \mathrm{mmol} \mathrm{L}^{-1}$. Reduction of the solution volume by half under reduced pressure afforded a brown precipitate which was isolated by filtration, washed with $\mathrm{Et}_{2} \mathrm{O}$, and

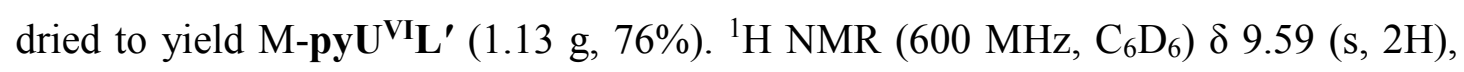
8.90 (s, 2H), 8.82 (d, J = 5.1 Hz, 1H), 8.63 (br. s, 2H, NH), 7.85 (d, J = 4.0 Hz, 1H, py), 7.80 (s, 2H), 7.71 (s, 2H), 7.47 (d, J = 8.5 Hz, 2H), 7.25 (d, J = 8.5 Hz, 2H, aryl), $7.23(\mathrm{~d}, \mathrm{~J}=3.7 \mathrm{~Hz}, 2 \mathrm{H}$, pyrrole), 7.06 (t, J = 8.5 Hz, 2H, aryl), 6.92 (t, 8.5 Hz, 2H, aryl), 6.87 (d, J = 8.5 Hz, 2H, aryl), 6.84 (d, J = 3.7 Hz, 2H, pyrrole), 6.27 (d, J = 8.5 $\mathrm{Hz}, 2 \mathrm{H}, \operatorname{aryl}), 6.20$ (d, J = 3.7 Hz, 2H, pyrrole), 5.95 (d, J = 3.7 Hz, 2H, pyrrole), 5.60 (t, J = 7.6 Hz, 1H, py), 5.55 (tt, J = 7.6, 1.7, 1H, py), 2.64 (q, J = 7.3 Hz, 2H), 2.49 (q, 
$\mathrm{J}=7.3 \mathrm{~Hz}, 2 \mathrm{H}), 2.06$ (q, J = 7.3 Hz, 2H), 1.53 (t, J = 7.3 Hz, 3H), 1.45 (q, J = 7.3 Hz, 2H), $1.01(\mathrm{t}, \mathrm{J}=7.3 \mathrm{~Hz}, 3 \mathrm{H}), 0.95(\mathrm{t}, \mathrm{J}=7.3 \mathrm{~Hz}, 3 \mathrm{H}), 0.49(\mathrm{t}, \mathrm{J}=7.3 \mathrm{~Hz}, 3 \mathrm{H}) ;{ }^{1} \mathrm{H}$ NMR (500 MHz, $\left.\mathrm{C}_{5} \mathrm{D}_{5} \mathrm{~N}\right) \delta 9.62(\mathrm{~s}, 2 \mathrm{H}), 9.38(\mathrm{~s} 2 \mathrm{H}), 8.16(\mathrm{~s}, 2 \mathrm{H}), 8.12(\mathrm{~s}, 2 \mathrm{H}), 7.74$ (d, J = 8.4 Hz, 2H, aryl), $7.50(\mathrm{~d}, \mathrm{~J}=3.7 \mathrm{~Hz}, 2 \mathrm{H}$, pyrrole), 7.33 (t, J = $7.8 \mathrm{~Hz}, 2 \mathrm{H}$, $\operatorname{aryl}), 7.26$ (t, J = 7.8 Hz, 2H, aryl), 7.04 (d, J = 7.1 Hz, 2H, aryl), 6.94 (d, J = 3.7 Hz, 2H, pyrrole), 6.62 (d, J = 7.1 Hz, 2H, aryl), 6.56 (d, J = 3.7 Hz, 2H, pyrrole), 6.15 (d, $\mathrm{J}=3.7 \mathrm{~Hz}, 2 \mathrm{H}$, pyrrole), $2.71(\mathrm{q}, \mathrm{J}=7.5 \mathrm{~Hz}, 2 \mathrm{H}), 2.55$ (q, J = 7.5 Hz, 2H), 2.18 (q, J $=7.5 \mathrm{~Hz}, 2 \mathrm{H}), 1.60(\mathrm{q}, \mathrm{J}=7.5 \mathrm{~Hz}, 2 \mathrm{H}), 1.48(\mathrm{t}, \mathrm{J}=7.5 \mathrm{~Hz}, 3 \mathrm{H}), 1.05(\mathrm{t}, \mathrm{J}=7.5 \mathrm{~Hz}$, $3 \mathrm{H}), 0.97(\mathrm{t}, \mathrm{J}=7.5 \mathrm{~Hz}, 3 \mathrm{H}), 0.54(\mathrm{t}, \mathrm{J}=7.5 \mathrm{~Hz}, 3 \mathrm{H}) ;{ }^{13} \mathrm{C} \mathrm{NMR}\left(125 \mathrm{~Hz}, \mathrm{C}_{5} \mathrm{D}_{5} \mathrm{~N}\right) \delta$ $162.8\left(\mathrm{C}_{\mathrm{q}}\right), 161.9(\mathrm{CH}), 156.9(\mathrm{CH}), 152.4\left(\mathrm{C}_{\mathrm{q}}\right), 149.9\left(\mathrm{C}_{\mathrm{q}}\right), 149.4(\mathrm{CH}), 139.1\left(\mathrm{C}_{\mathrm{q}}\right)$, $133.0\left(\mathrm{C}_{\mathrm{q}}\right), 131.5\left(\mathrm{C}_{\mathrm{q}}\right), 128.9\left(\mathrm{C}_{\mathrm{q}}\right), 128.7\left(\mathrm{C}_{\mathrm{q}}\right), 128.5\left(\mathrm{C}_{\mathrm{q}}\right), 127.7\left(\mathrm{C}_{\mathrm{q}}\right), 126.9(\mathrm{CH})$, $126.6(\mathrm{CH}), 125.7(\mathrm{CH}), 125.6(\mathrm{CH}), 125.5(\mathrm{CH}), 120.9(\mathrm{CH}), 120.4(\mathrm{CH}), 117.5$ $(\mathrm{CH}), 113.6(\mathrm{CH}), 112.2(\mathrm{CH}), 108.6(\mathrm{CH}), 52.2\left(\mathrm{C}_{\mathrm{q}}\right.$, meso carbon $), 43.8\left(\mathrm{C}_{\mathrm{q}}\right.$, meso carbon), $40.3\left(\mathrm{CH}_{2}\right), 36.4\left(\mathrm{CH}_{2}\right), 27.3\left(\mathrm{CH}_{2}\right), 26.7\left(\mathrm{CH}_{2}\right), 11.5\left(\mathrm{CH}_{3}\right), 11.0\left(\mathrm{CH}_{3}\right), 8.9$ $\left(\mathrm{CH}_{3}\right), 8.5\left(\mathrm{CH}_{3}\right)$; Anal. Calcd. $\mathrm{C}_{63} \mathrm{H}_{55} \mathrm{~N}_{9} \mathrm{O}_{2} \mathrm{U}$ (1208.22) requires $\mathrm{C} \% 62.63, \mathrm{H} \%$ 4.59, $\mathrm{N} \% 10.43$; found C \% 62.42, H \% 4.63, N \% 10.28 .

M-THFU $\left.{ }^{\mathrm{VI}} \mathbf{L}^{\prime} . \mathrm{H}_{4} \mathrm{~L}^{\prime}(50.0 \mathrm{mg}, 0.58 \mathrm{mmol}, 1 \text { eq.) and [(THF) })_{2}\left(\mathrm{UO}_{2}\right)\left(\mathrm{N}\left(\mathrm{SiMe}_{3}\right)_{2}\right)_{2}\right]$ (42.7 mg, $0.58 \mathrm{mmol}, 1$ eq.) were each dissolved in ca. $0.5 \mathrm{~mL}$ of $\mathrm{C}_{6} \mathrm{D}_{6}$ and the solutions mixed at room temperature. Analysis of the brown mixture by ${ }^{1} \mathrm{H}$ NMR spectroscopy after 10 min demonstrated complete conversion to $\mathbf{M}-\mathbf{T H F} \mathbf{U}^{\mathbf{V I}} \mathbf{L}^{\prime}$ with no resonances remaining for $\mathrm{H}_{4} \mathrm{~L}^{\prime}$ or the uranium starting material (M-THFU ${ }^{\mathbf{V I}} \mathbf{L}^{\prime}$ shows slight solubility in $\mathrm{C}_{6} \mathrm{D}_{6}$ ). The mixture was centrifuged and the resultant brown powder was washed with hexane to yield $\mathbf{M}-\mathbf{T H F U}^{\mathbf{V I}} \mathbf{L}^{\prime}(41.3 \mathrm{mg}, 34 \%) .{ }^{1} \mathrm{H}$ NMR $\delta$ (500 MHz, $\left.\mathrm{C}_{6} \mathrm{D}_{6}\right) 9.89$ (s, 2H), 8.99 (s 2H), 8.16 (s, 2H), 8.12 (s, 2H), 7.84 (s, 2H), $7.62(\mathrm{~d}, \mathrm{~J}=8.7 \mathrm{~Hz}, 2 \mathrm{H}$, aryl), $7.55(\mathrm{~d}, \mathrm{~J}=7.0 \mathrm{~Hz}, 2 \mathrm{H}$, aryl), $7.10(\mathrm{~m}, 2 \mathrm{H}), 6.78(\mathrm{~s}, 2 \mathrm{H})$, 6.49 (d, J = 5.1 Hz, 2H, pyrrole), 6.23 (s, 2H), 5.94 (s, 2H), 4.08 (t, J = 6.6 Hz, 2H, THF), 3.34 (t, J = 6.6 Hz, 2H), 2.58 (q, J = 7.3 Hz, 2H), 2.47 (q, J = 7.3 Hz, 2H), 2.02 (q, J = 7.3 Hz, 2H), $1.57(\mathrm{t}, \mathrm{J}=6.6 \mathrm{~Hz}, 2 \mathrm{H}), 1.25$ (q, J = $7.3 \mathrm{~Hz}, 2 \mathrm{H}), 0.90(\mathrm{~m}, 6 \mathrm{H})$, $0.40(\mathrm{t}, \mathrm{J}=7.3 \mathrm{~Hz}, 3 \mathrm{H}),-0.85(\mathrm{t}, \mathrm{J}=7.3 \mathrm{~Hz}, 3 \mathrm{H}) ;{ }^{13} \mathrm{C} \mathrm{NMR}\left(500 \mathrm{MHz}, \mathrm{C}_{6} \mathrm{D}_{6}\right) 162.7$ $\left(\mathrm{C}_{\mathrm{q}}\right), 161.9(\mathrm{CH}), 151.6\left(\mathrm{C}_{\mathrm{q}}\right), 149.0\left(\mathrm{C}_{\mathrm{q}}\right), 148.1(\mathrm{CH}), 143.2\left(\mathrm{C}_{\mathrm{q}}\right), 138.4\left(\mathrm{C}_{\mathrm{q}}\right), 133.0$ 
$\left(\mathrm{C}_{\mathrm{q}}\right), 132.7\left(\mathrm{C}_{\mathrm{q}}\right), 130.6\left(\mathrm{C}_{\mathrm{q}}\right), 129.1\left(\mathrm{C}_{\mathrm{q}}\right), 128.1(\mathrm{CH}), 126.5(\mathrm{CH}), 126.4(\mathrm{CH}), 125.7$ $(\mathrm{CH}), 125.1(\mathrm{CH}), 125.1(\mathrm{CH}), 124.8(\mathrm{CH}), 120.7(\mathrm{CH}), 119.8(\mathrm{CH}), 117.2(\mathrm{CH})$, $112.8(\mathrm{CH}), 111.2(\mathrm{CH}), 107.3(\mathrm{CH}) 76.4\left(\mathrm{CH}_{2}\right), 73.9\left(\mathrm{CH}_{2}\right), 43.0\left(\mathrm{CH}_{2}\right), 30.7\left(\mathrm{CH}_{2}\right)$, $25.4\left(\mathrm{CH}_{2}\right), 24.8\left(\mathrm{CH}_{2}\right), 24.6\left(\mathrm{CH}_{2}\right), 24.0\left(\mathrm{CH}_{2}\right), 11.0\left(\mathrm{CH}_{3}\right), 9.8\left(\mathrm{CH}_{3}\right), 8.0\left(\mathrm{CH}_{3}\right), 7.7$ $\left(\mathrm{CH}_{3}\right)$.

B-py $\mathbf{U}^{\mathbf{V I}} \mathbf{L}^{\prime}$. This is an updated route to a previously characterized complex. ${ }^{38}$ To a $\mathrm{d}_{5}$-pyridine solution of $\mathrm{H}_{4} \mathrm{~L}^{\prime}(50.0 \mathrm{mg}, 0.58 \mathrm{mmol}, 1$ eq.) was added a solution of $\left[(\mathrm{THF})_{2}\left(\mathrm{UO}_{2}\right)\left(\mathrm{N}\left(\mathrm{SiMe}_{3}\right)_{2}\right)_{2}\right](106.7 \mathrm{mg}, 1.45 \mathrm{mmol}, 2.5$ eq. $)$ in pyridine. The solution darkened immediately and a dark precipitate formed. The solution was centrifuged and the brown powder isolated by decantation, washed with hexanes, and dried to yield B-pyU $\mathbf{U}^{\mathrm{VI}^{\prime}} \mathbf{L}^{\prime}$ as a brown powder. Yield: $76.2 \mathrm{mg}, 85 \%$. Vapor diffusion of hexanes into a pyridine solution yielded crystalline material which was analysed by ${ }^{1} \mathrm{H}$ NMR spectroscopy (B-py $\mathbf{U}^{\mathbf{V I}} \mathbf{L}^{\prime}$ shows slight dissolution in $\mathrm{d}_{5}$-pyridine) and found to be B-py $\mathbf{U}^{\mathrm{VI}} \mathbf{L}^{\prime}$.

B-THFU ${ }^{\mathrm{VI}} \mathbf{L}^{\prime}$. [ $\{\mathrm{U}(\mathrm{OAr})\}_{2}($ endo-BH $\left.4 \mathrm{~K})\left(\mathrm{L}^{\prime}\right)(\mathrm{THF})_{2}\right](12 \mathrm{mg}, 0.006 \mathrm{mmol})$ was suspended in $\mathrm{C}_{6} \mathrm{D}_{6}(0.5 \mathrm{~mL})$ in a Teflon-tapped NMR tube. The mixture was freeze-pump-thaw degassed three times and an atmosphere of dry $\mathrm{O}_{2}$ was introduced. An immediate colour change from dark green to dark red occurred. The ${ }^{1} \mathrm{H}$ NMR spectrum contains resonances corresponding to a mixture of paramagnetic and diamagnetic compounds. Dark red crystals formed in the stored mixture over $4 \mathrm{~d}$ which were analysed by X-ray diffraction and found to be B-THFU ${ }^{\mathbf{V I}} \mathbf{L}^{\prime}$. Given its similarity to the above pyridine adduct, no further characterization of this complex was carried out.

\section{Results and Discussion}

\subsection{Computed structural properties}

\subsubsection{Bis-uranyl(VI) complexes}




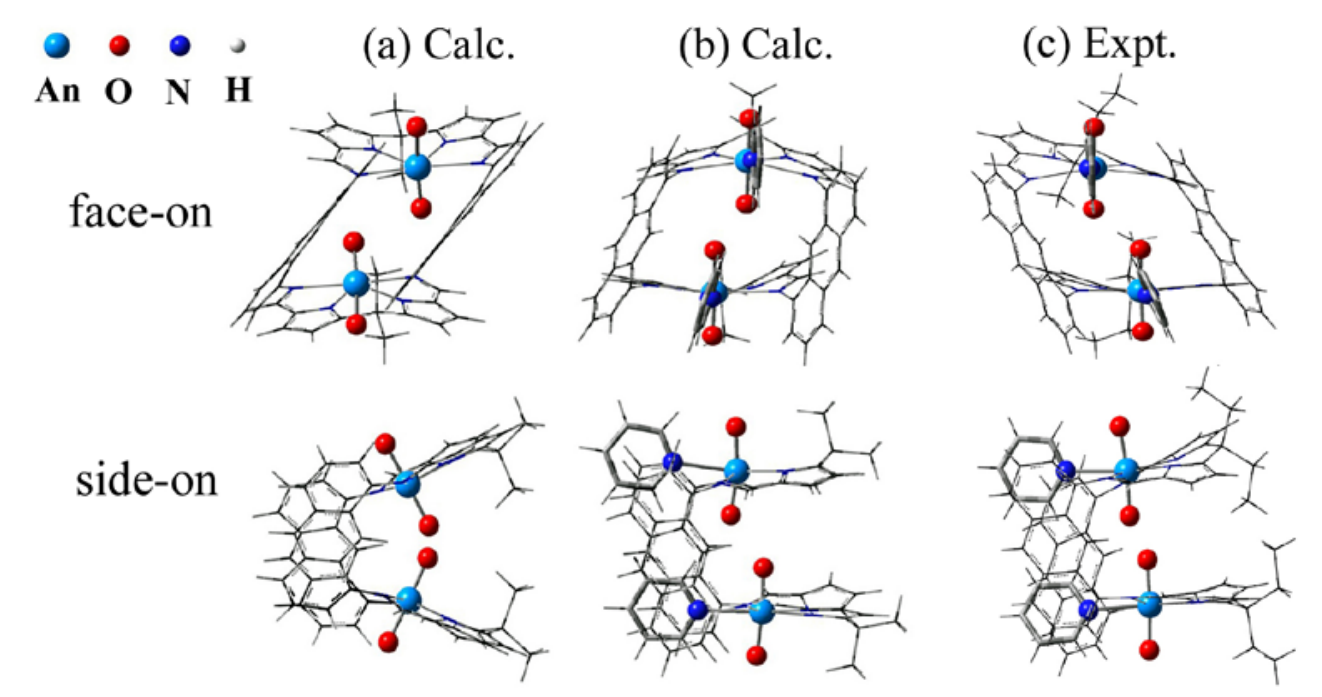

Figure 1. Optimised structures of binuclear actinyl complexes $\left[(\mathrm{sol})_{2}\left(\mathrm{An}^{\mathrm{m}} \mathrm{O}_{2}\right)_{2}(\mathrm{~L})\right]^{2 \mathrm{n}-4}(\mathrm{~m}=\mathrm{VI}, \mathrm{n}$ $=2 ; \mathrm{m}=\mathrm{V}, \mathrm{n}=1 ; \mathrm{An}=\mathrm{U}, \mathrm{Np}$ and $\mathrm{Pu}$ ): (a) sol = vacant and (b) sol = pyridine. (c) The structure of $\left[(\mathrm{py})_{2}\left(\mathrm{U}^{\mathrm{VI}} \mathrm{O}_{2}\right)_{2}\left(\mathrm{~L}^{\prime}\right)\right]$ obtained in our present and previous ${ }^{38}$ experimental work.

The bis-uranyl complex (B-U $\left.\mathbf{U}^{\mathbf{V I}}\right)$, that does not include the additional pyridine molecule in the fifth equatorial coordination site around each uranyl ion, was previously found to have a Pacman-like structure, Figure 1a (Calculation). ${ }^{41}$ The bite angle ( $\alpha$, Chart 3 ) between the two $\mathrm{N}_{4}$-donor compartmental planes of $41^{\circ}$ (Table 1) reflects significant deviation from co-planarity. The lateral twist angle $(\beta)$ of the macrocycle was calculated to be $38^{\circ}$, which combines with the above-mentioned vertical expansion away from co-planarity to decrease the repulsion between the endo-endo oxygen atoms. The $\mathrm{O}_{\text {endo }} \cdots \mathrm{O}_{\text {endo }}$ distance was optimised at $2.94 \AA$. However, this structure is different from that which was experimentally obtained (B-py $\mathbf{U}^{\mathbf{V I}^{\prime}} \mathbf{L}^{\prime}$ in Figure 1c), ${ }^{38}$ although both retain a generally similar skeleton. These differences between experiment and the optimised B-U $\mathbf{U}^{\mathbf{V I}}$ are as large as $24^{\circ}(\alpha), 16^{\circ}$ $(\beta), 49^{\circ}\left(\theta(\mathrm{s})\right.$, the angle between the two linear $\mathrm{UO}_{2}{ }^{2+}$ rods in the side-on projection) and $2.56 \AA$ ( $\mathrm{D}$, the normal distance between the two anthracenyl planes). For definitions of $\alpha, \beta, \theta(\mathrm{f})$ and $\theta(\mathrm{s})$ and $\mathrm{D}$, see Chart 3 . 

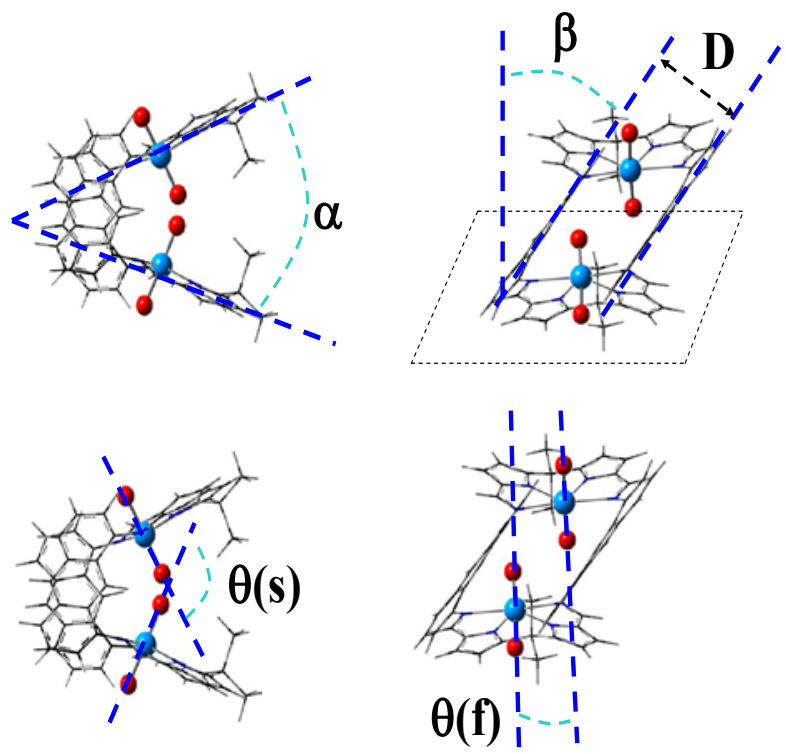

Chart 3. Definition of geometry parameters. The bite angle $(\alpha)$ is the dihedral angle between the two $\mathrm{N}_{4}$-donor compartmental planes. The twist angle $(\beta)$ is the difference between a right angle $\left(90^{\circ}\right)$ and the angle (mean) between the $\mathrm{N}_{4}$-donor plane and the anthracenyl hinge plane. The actinyl angles $(\theta)$ denote the angle between two approximately linear actinyl rods in a side on $(\theta(\mathrm{s}))$ and face on $(\theta(\mathrm{f}))$ projection, respectively. The distance (D), the normal distance (mean) between the two anthracenyl planes, is measured from the centroid of one anthracenyl plane to the line formed by three centroids of benzene rings of the other anthracenyl plane.

We have investigated three likely causes for the discrepancy between calculation and experiment. (i) In our previous calculations, ${ }^{41}$ we omitted the equatorial pyridine ligand to save computational cost. This pyridine-free B-U $\mathbf{U}^{\mathbf{V I}}$ differs from the pyridine-solvated B-py $\mathbf{U}^{\mathbf{V I}} \mathbf{L}^{\prime}$ that was experimentally obtained. (ii) Optimization of B-U $\mathbf{U}^{\mathbf{V I}}$ was performed in the gas phase, while the experiment was performed on a single crystal where molecular packing (effects of condensed medium) of the real complex may influence the structure. (iii) Ligand simplification was used, i.e. the ligand L replacing the experimental $\mathrm{L}^{\prime}$. Please see above (i) and (iii) in Chart S1 in the Supporting Information.

Here, we have optimised B-py $\mathbf{U}^{\mathbf{V I}}$ to probe the effect of explicit pyridine coordination on the structure and find that the calculated structure that includes equatorial pyridine is now similar to the experimental one, Figures $1 \mathrm{~b}$ and $1 \mathrm{c}$. A co-facial orientation of the $\mathrm{N}_{4}$-donor compartments (bite angle $\alpha$ of $17^{\circ}$ ) and co-linear bis-uranyl $\left(\theta(\mathrm{f})\right.$ of $177^{\circ}$ and $\theta(\mathrm{s})$ of $175^{\circ}$ ) are found, agreeing well with the 
experimental values of $17^{\circ}, 177^{\circ}$ and $173^{\circ}$, respectively (Table 1). Moreover, the normal distance (D) between the two anthracenyl planes is also approaching the experimental value to within $5 \%$. As a direct result of sterics, the inclusion of equatorial pyridines causes the two anthracenyl planes to depart from each other. On the other hand, the repulsion between the two pyridines, to some degree, forces the two $\mathrm{N}_{4}$-donor compartments to approach each other.

To simulate the effects of the surrounding condensed medium of solvent on the real complex, we have used the COSMO model, which implicitly incorporates a self-consistent reaction field around the complex. Both pyridine-free B- $\mathbf{U}^{\mathbf{V I}}$ and pyridine-solvated B-py $\mathbf{U}^{\mathbf{V I}}$ were optimised in the gas phase and in pyridine solution using the PBE/B-II/ZORA approach. The condensed-phase environment does not change the overall general geometry of the complex (Table 1), but has a slight effect on specific geometry parameters (Table S3).

In addition to using the GGA-PBE functional, more functionals including GGA-BP86, Meta-GGA (TPSS and M06L) and hybrid (B3LYP and PBE0) were used to optimize B-U $\mathbf{U}^{\mathbf{V I}}$ and B-pyU $\mathbf{U}^{\mathbf{V I}}$. The approach is labeled as A4 (Gaussian: DFT/B-III/RLC-ECP/gas) $)^{77}$. See computational details in Table S3. Comparison with experimental values find that the overall geometry parameters $(\alpha, \beta, \theta$, and $\mathrm{D})$ of B-py $\mathbf{U}^{\mathbf{V I}}$ are closer to experimental values than those of B-U ${ }^{\mathbf{V I}}$, regardless of what functional is used. Regarding specific geometry parameters of B-pyU $\mathbf{U}^{\mathrm{VI}}$, the choice of functional has some effects. As seen in Table S3, the GGA (PBE) and Meta-GGA (TPSS) yield relatively long bond lengths relative to experimental values, while the hybrid (B3LYP and PBE0) and Meta-GGA M06L give slightly short ones. This is related to the nature of functional that GGA tends to overestimate bond lengths and hybrid underestimates them. For example, the difference of $\mathrm{U}-\mathrm{O}_{\mathrm{exo}} / \mathrm{O}_{\text {endo }}$ bond lengths between GGA/Meta-GGA calculations and experiment is less than $0.05 \AA$; the hybrid shows relatively small difference within $0.03 \AA$. In brief, the PBE functional used in this work is reliable for the structural optimizations.

By comparison, the B-py $\mathbf{U}^{\mathrm{VI}}$ is a good computational model to represent B-py $\mathbf{U}^{\mathbf{V I}} \mathbf{L}^{\prime}$ as seen in Tables 1 and 2. Most values calculated for B-py $\mathbf{U}^{\mathbf{V I}}$ and 
B-py $\mathbf{U}^{\mathrm{VI}} \mathbf{L}^{\prime}$ are close to the experimentally measured values of B-py $\mathbf{U}^{\mathbf{V I}} \mathbf{L}^{\prime}$. Due to the different steric effects, the terminal groups' simplification mainly affects $\alpha$ (bite angle) / $\beta$ (twist angle). Those were calculated to be $17.0^{\circ} / 13.2^{\circ}$ (B-py $\mathbf{U}^{\mathrm{VI}}$ ) and $23.1^{\circ} / 17.9^{\circ}$ (B-py $\mathbf{U}^{\mathbf{V I}} \mathbf{L}^{\prime}$ ), respectively. This can be compared to the experimental values $16.8^{\circ} /$ 22.6 $6^{\circ}$ Similar cases are found for the mononuclear complexes M-solU ${ }^{\mathbf{V I}}$ and M-solU ${ }^{\mathbf{V I}} \mathbf{L}^{\prime}$ (sol = pyridine and THF) as shown in Tables 3 and S2.

These comparisons indicate that the equatorially U-coordinating pyridine solvent molecule is essential in calculations to obtain the same molecular geometry as that obtained by crystallography, while, on the other hand, the inclusion of bulk solvent and ligand simplification have only a slight effect. We conclude that B-py $\mathbf{U}^{\mathbf{V I}}$ optimised in the gas phase is a reasonable model to represent the experimentally obtained real complex.

The calculated geometry parameters of B-py $\mathbf{U}^{\mathbf{V I}}$ at the Priroda: PBE/B-I/AE level are listed in Table 2. The $\mathrm{U}=\mathrm{O}_{\text {exo }}$ and $\mathrm{U}=\mathrm{O}_{\text {endo }}$ bond lengths were calculated to be 1.81 and $1.80 \AA$ (mean values), respectively. The difference relative to the corresponding experimental values falls within $0.03 \AA$, which mainly originates from the GGA-PBE functional overestimating the bond lengths. ${ }^{78,79}$ Similarly, the calculated $U-N_{p y}$ bond lengths (2.63-2.65 $\AA)$ are slightly longer than the experimental ones (2.57-2.61 $\AA$ ).

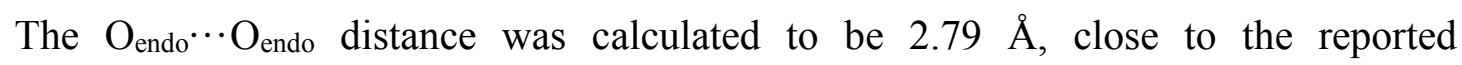
experimental value of $2.71 \AA$. The two uranyl ions remain approximately linear with $\mathrm{O}=\mathrm{U}=\mathrm{O}$ angles of $171^{\circ}-174^{\circ}$. The calculated $\mathrm{U}=\mathrm{O}$ bond orders range from 2.37 to 2.39 , suggesting partial triple bonding character, as is normally found for uranyl (VI) complexes. The dative bond from the equatorial pyridine to the uranium centre is found to be very weak, reflected by the calculated $U-\mathrm{N}_{\mathrm{py}}$ bond order of $0.34-0.35$.

\subsubsection{Other Bis-actinyl Complexes}

All of the pyridine-solvated bis-actinyl complexes (U, Np, Pu; VI and V) have been optimised and exhibit geometries with approximately co-facial $\mathrm{N}_{4}$-donor compartments and co-linear bis-actinyl fragments. A lateral twist of the macrocycle combined with a slight vertical expansion away from co-planarity decreases the repulsion between the endo-endo oxo atoms. Regarding An(VI) actinyls, the variation 
of the actinide element from $\mathrm{UO}_{2}{ }^{2+}$ to $\mathrm{NpO}_{2}{ }^{2+}$ to $\mathrm{PuO}_{2}{ }^{2+}$ does not have an effect on the general geometry of the complexes (see Table 1). In contrast, relatively large changes are found upon varying the oxidation state (VI and V) of the actinide. This is attributed to the more basic nature of the endo-oxo of actinyl(V) compared to the corresponding actinyl(VI). The stronger repulsion between the two endo-oxo atoms in bis-actinyl(V) complexes leads to bigger bite angles $\alpha$ (deviation from co-planarity), smaller $\theta(\mathrm{s})$ angles as well as longer $\mathrm{U} \cdots \mathrm{U}$ and $\mathrm{O}_{\text {endo }} \cdots \mathrm{O}_{\text {endo }}$ distances (Table 1).

For both $\mathrm{An}(\mathrm{VI})$ and $\mathrm{An}(\mathrm{V})$ complexes, the calculated $\mathrm{An}=\mathrm{O}$ bond lengths and bond orders gradually decrease in the order $\mathrm{U}>\mathrm{Np}>\mathrm{Pu}$, Table 2 in agreement with the actinide contraction; similar trends have been found for other actinyl complexes. ${ }^{79}$ Relative to those of An(VI) B-pyAn ${ }^{\mathrm{VI}}$, the $\mathrm{An}=\mathrm{O}$ bond distances of $\mathrm{An}(\mathrm{V}) \mathrm{B}-\mathbf{p y} \mathbf{A n} \mathbf{V}$ are lengthened by $0.01-0.04 \AA$. This elongation of the $\mathrm{An}=\mathrm{O}$ bonds associated with the $\mathrm{An}(\mathrm{VI}) \rightarrow \mathrm{An}(\mathrm{V})$ reduction is consistent with previous theoretical ${ }^{7,}$ 79-82 and experimental reports ${ }^{8,13,32,83,84}$.

With the ADF code, B-pyU $\mathbf{U I}^{\mathrm{VI}}$ was calculated with various functionals including GGA-PBE, Meta-GGA-TPSS and hybrid B3LYP. The unoccupied orbitals were focused on, which would provide insight into not only electronic properties of bis-uranium(VI) complex, but also those of bis-transuranium(VI) ones for their extra electrons would be presumed to fill the unoccupied orbitals of uranium(VI). As seen in Figure S1, similar electronic arrangement is found in calculations of different functionals, except that the hybrid B3LYP shows larger HOMO-LUMO gap energy than the GGA and Meta-GGA functional. The PBE results display fifteen $\mathrm{U}(5 f)$-character virtual orbitals, including four $f(\phi)$, four $f(\delta)$, five $f(\pi)$ and two $f(\sigma)$. Notably, diagrams of orbitals in Figure S2 show one pyridine orbital is mixing with $f(\pi)$ in $\mathrm{LUMO}+19$ and $\mathrm{LUMO}+21$. Therefore, these $\mathrm{U}(5 f)$-character virtual orbitals comply with fourteen $5 f$-electron orbitals that bis-uranium complexes generally possess. The $f(\phi)$ and $f(\delta)$ orbitals of B-py $\mathbf{U}^{\mathbf{V I}}$ were calculated to be in the low-energy area, so the extra $5 f$ electrons are supposed into these orbitals in transuranium complexes, B-pyNp ${ }^{\mathrm{VI}}$ and B-pyPu ${ }^{\mathrm{VI}}$. 


\subsubsection{Mononuclear actinyl complexes}

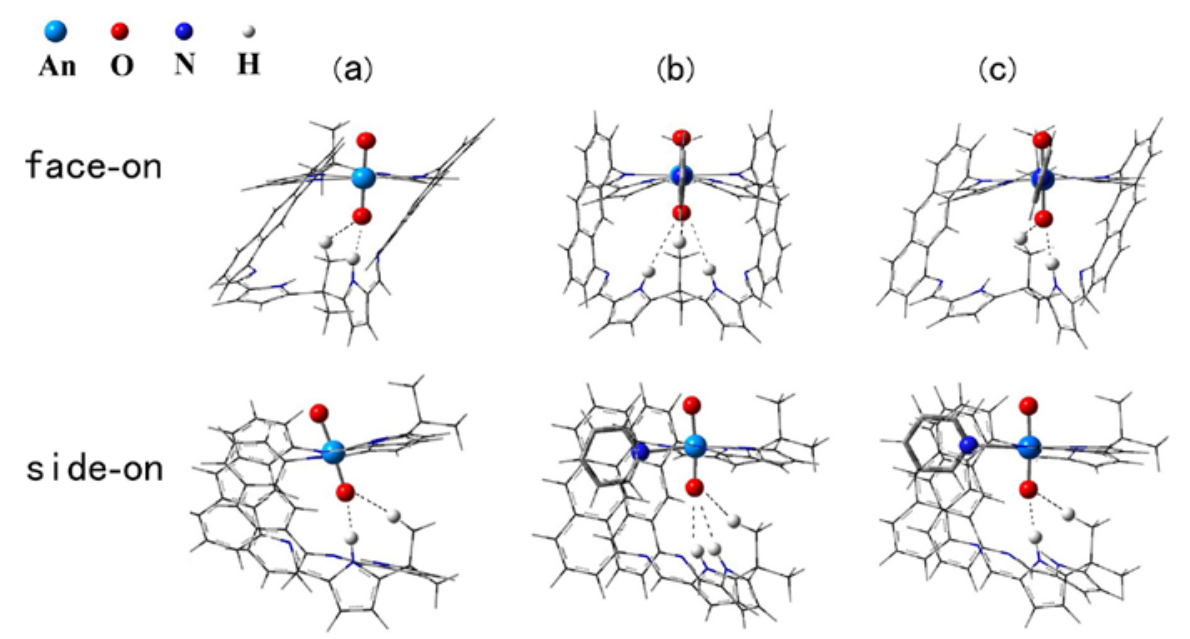

Figure 2. Optimised structures of mononuclear actinyl complexes $\left[(\mathrm{sol})\left(\mathrm{An}^{\mathrm{m}} \mathrm{O}_{2}\right)\left(\mathrm{H}_{2} \mathrm{~L}\right)\right]^{\mathrm{n}-2}(\mathrm{~m}=\mathrm{VI}$, $\mathrm{n}=2 ; \mathrm{m}=\mathrm{V}, \mathrm{n}=1 ; \mathrm{An}=\mathrm{U}, \mathrm{Np}$ and $\mathrm{Pu}$ ): (a) sol = vacant and (b) sol = pyridine, together with (c) the pyridine-solvated $\left[(\mathrm{py})\left(\mathrm{Pu}^{\mathrm{V}} \mathrm{O}_{2}\right)\left(\mathrm{H}_{2} \mathrm{~L}\right)\right]^{-}$.

Optimizations indicated that all the mononuclear complexes, M-pyAn ${ }^{\mathbf{m}}(\mathrm{m}=\mathrm{VI}$ and V), display co-facial molecular geometries (Table 1 and Figure 2). A moderate lateral twist of the macrocycle is found for most, that is, twist angles $(\beta)$ calculated to be less than $7^{\circ}$. Each of them has two different hydrogen bonds to the endo-oxo atom: $\mathrm{O}_{\text {endo }} \cdot \mathrm{H}\left(\mathrm{N}_{\text {pyrrolide }}\right)(2.94-3.32 \AA)$ and $\mathrm{O}_{\text {endo }} \cdot \cdot \mathrm{H}\left(\mathrm{C}_{\text {terminal }}\right)(2.37-2.49 \AA)$, Table 3. However, $\mathbf{M}-\mathbf{p y P u} \mathbf{u}^{\mathbf{v}}$ is exceptional, having a lateral twist in the structure with $\beta=23^{\circ}$. Consequently, a very short $\mathrm{O}_{\text {endo }} \cdot \mathrm{H}(\mathrm{N})$ hydrogen bond distance was obtained at 2.15 $\AA$, together with a long one at $3.66 \AA$. To further prove its structural stability, we also performed the following calculations: i) to optimise the structure of $\mathbf{M}-\mathbf{p y P u} \mathbf{u}^{\mathbf{v}}$ starting from stable geometries of the $\mathrm{U}^{\mathrm{V}} / \mathrm{Np}^{\mathrm{V}}$ complexes that do not show ligand distortion; and ii) to optimise other complexes starting from the twisted structure of the $\mathrm{Pu}^{\mathrm{V}}$ complex. All the results converge to the same twisted structure and therefore support the conclusion that $\mathbf{M}-\mathbf{p y P u} \mathbf{u}^{\mathbf{V}}$ is different. Most geometry parameters of M-py $\mathbf{U}^{\mathbf{V I}}$ and M-py $\mathbf{U}^{\mathbf{V I}} \mathbf{L}^{\prime}$ were calculated to be in agreement with the experimental data from X-ray crystal diffraction.

\subsection{Experimental Synthesis}

Previously, in experimental studies, treatment of $\mathrm{H}_{4} \mathrm{~L}^{\prime}$ with either one or two 
equivalents of $\left[(\mathrm{py})_{2}\left(\mathrm{UO}_{2}\right)\left(\mathrm{N}\left(\mathrm{SiMe}_{3}\right)_{2}\right)_{2}\right]$ yielded mixtures of the uranyl complexes M-py $\mathbf{U}^{\mathbf{I V}} \mathbf{L}^{\prime}$ and B-py $\mathbf{U}^{\mathbf{V I}} \mathbf{L}^{\prime}$ (Chart 2). ${ }^{38}$ The reaction with two equivalents of the uranyl precursor gives a higher yield of $\mathrm{B}-\mathbf{p y}^{\mathbf{V I}} \mathbf{L}^{\prime}(50 \%$ vs. $15 \%)$, but in approximately a 1:1 ratio with the mono, $\mathbf{M}-\mathbf{p y} \mathbf{U}^{\mathbf{V I}} \mathbf{L}^{\prime}$. X-ray quality crystals of the pyridine adducts were grown because of the higher crystallinity of this solvate. In this work, we have developed the synthetic route to allow direct access to, and clean

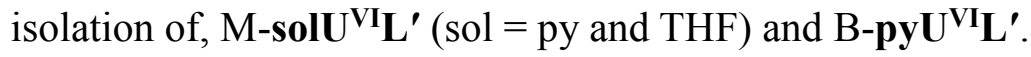

Treatment of $\mathrm{H}_{4} \mathrm{~L}^{\prime}$ with one equivalent of $\left[(\mathrm{py})_{2}\left(\mathrm{UO}_{2}\right)\left(\mathrm{N}\left(\mathrm{SiMe}_{3}\right)_{2}\right)_{2}\right]$ in benzene or toluene at room temperature cleanly yields $\mathbf{M}-\mathbf{p y} \mathbf{U}^{\mathbf{V I}} \mathbf{L}^{\prime}$ as a brown precipitate which was isolated by filtration and washed with $\mathrm{Et}_{2} \mathrm{O}$ or hexane. X-ray quality crystals were grown by slow cooling a concentrated solution of $\mathbf{M}-\mathbf{p y} \mathbf{U}^{\mathbf{V I}^{\mathbf{I}}} \mathbf{L}^{\prime}$ in pyridine (Figure 3).

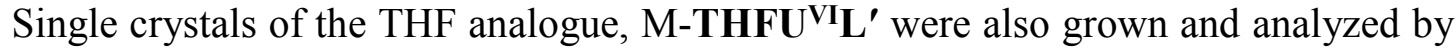
X-ray diffraction (Figure 3).

Treatment of $\mathrm{H}_{4} \mathrm{~L}^{\prime}$ with two equivalents of $\left[(\mathrm{py})_{2}\left(\mathrm{UO}_{2}\right)\left(\mathrm{N}\left(\mathrm{SiMe}_{3}\right)_{2}\right)_{2}\right]$ in $d_{5}$-pyridine

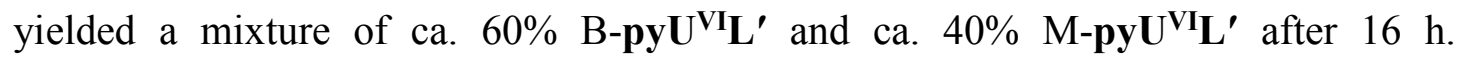
Complete conversion to B-py $\mathbf{U}^{\mathbf{V I}} \mathbf{L}^{\prime}$ is achieved upon treatment of $\mathrm{H}_{4} \mathrm{~L}^{\prime}$ with 2.5 equivalents of $\left[\left(\mathrm{py}_{2}\left(\mathrm{UO}_{2}\right)\left(\mathrm{N}\left(\mathrm{SiMe}_{3}\right)_{2}\right)_{2}\right]\right.$ in pyridine solvent for $2 \mathrm{~h}$. B-py $\mathbf{U}^{\mathrm{VI}} \mathbf{L}^{\prime}$ precipitates as a brown solid that was isolated by centrifugation followed by washing with hexane.

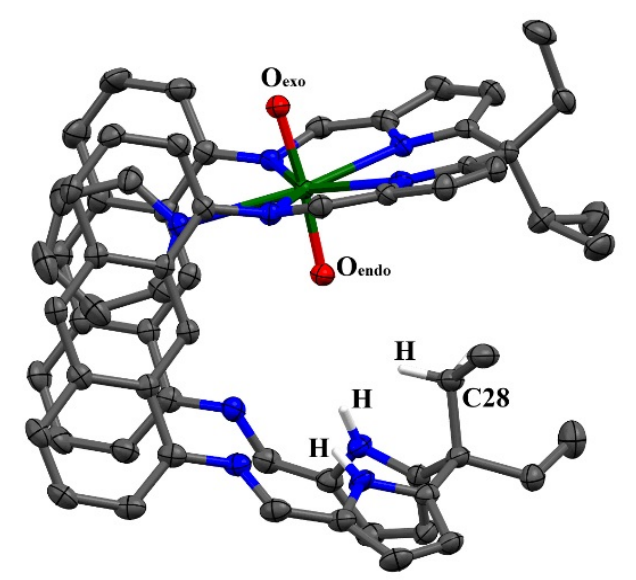

Figure 3. Solid state structure of $\mathrm{M}-\mathbf{p y} \mathbf{U}^{\mathrm{VI}} \mathbf{L}^{\prime}$ determined by X-ray crystallography. For clarity, all hydrogens except the pyrrolic NH and those on C28 are omitted (displacement ellipsoids are drawn at $50 \%$ probability). Selected distances and angles are shown in Tables 1, 2 and S2. 
We are able to isolate crystals of the THF adduct of this binuclear complex via a different route. Treatment of a benzene solution of $\mathrm{K}\left[\left((\mathrm{ArO}) \mathrm{U}^{\mathrm{IV}}\right)_{2} \mathrm{~L}^{\prime}\left(\mathrm{BH}_{4}\right)\right]$ with excess $\mathrm{O}_{2}$ yields a mixture of paramagnetic species. Upon standing for 4 days, dark red crystals formed in this solution which were analyzed by X-ray diffraction and found to be B-THFU ${ }^{\mathrm{VI}} \mathbf{L}^{\prime}$ (Figure S5).

\subsection{Redox Potentials}

The single-electron reduction reactions of mono- and binuclear actinyl complexes $\left(\mathrm{U}^{\mathrm{VI}}\right.$ to $\left.\mathrm{U}^{\mathrm{V}}\right)$ were theoretically and experimentally investigated. The calculated energies $(\mathrm{eV})$ in the gas phase and pyridine are presented in Table 4, together with the available experimental results. With respect to the reference ferrocene/ferrocenium couple $\left(\mathrm{Fc}^{+} / \mathrm{Fc}\right)$, we have calculated the free energy $\left(\Delta_{\mathrm{r}} \mathrm{G}(\mathrm{sol})\right)$ of the following reaction:

$$
\begin{aligned}
& \left(\mathrm{An}^{\mathrm{VI}} \text { complex }\right)+\mathrm{Fc} \rightarrow\left(\mathrm{An}^{\mathrm{V}} \text { complex }\right)+\mathrm{Fc}^{+} \\
& \mathrm{E}^{0}=-\Delta_{\mathrm{r}} \mathrm{G}(\mathrm{sol}) / \mathrm{F}
\end{aligned}
$$

Then according to Eq. (2) where $\mathrm{F}$ is the Faraday constant the reduction potential $\left(\mathrm{E}^{0}\right.$ in V) was obtained. Experimental cyclic voltametry (CV) was also undertaken on both $\mathrm{M}-\mathbf{p y} \mathbf{U}^{\mathrm{VI}} \mathbf{L}^{\prime}$ and B-py $\mathbf{U}^{\mathbf{V I}} \mathbf{L}^{\prime}$. Our previously reported $\mathrm{CV}$ data were collected using $\left[n\right.$-Bu $\left.\mathrm{Bu}_{4}\right]\left[\mathrm{BF}_{4}\right]$ electrolyte; ${ }^{38}$ however the use of $\left[n-\mathrm{Bu}_{4} \mathrm{~N}\right]\left[\mathrm{BPh}_{4}\right]$ appears to give less electrode fouling and has allowed us to observe the $\mathrm{UO}_{2}$ reduction chemistry clearly.

The reduction potential of the mononuclear uranyl complex (M-pyU) from VI to V was calculated to be $-1.56 \mathrm{~V}$ after considering solvation and spin-orbit coupling (SOC) correction. ${ }^{80}$ This is in excellent agreement with the experimental result which showed a half-wave potential $\mathrm{E}_{1 / 2}$ value of $-1.57 \mathrm{~V}$ (a quasi-reversible reduction of

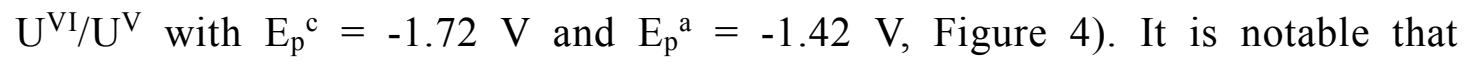




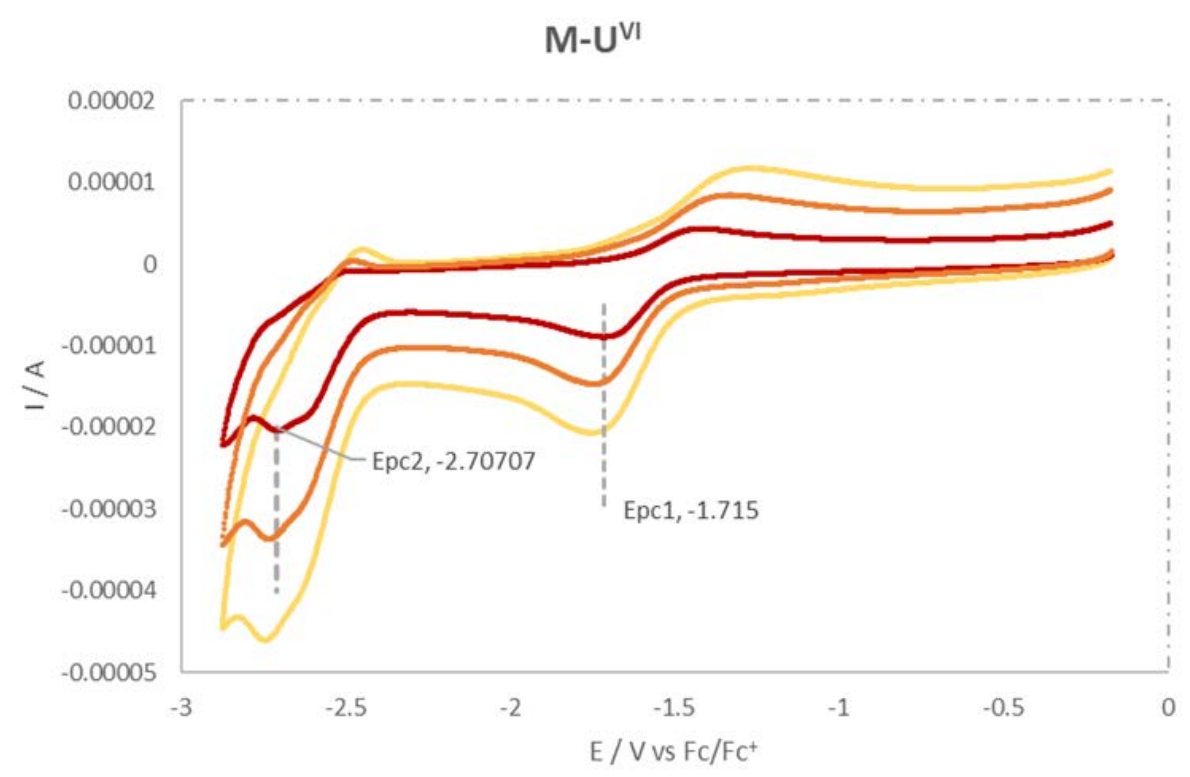

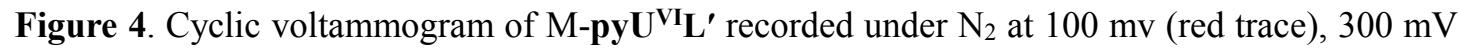
(orange trace) and $500 \mathrm{mV}$ (yellow trace) in the range $-0.2 \mathrm{~V}$ to $-2.8 \mathrm{~V}$. Conditions: $1 \mathrm{mM}$ of M-pyU ${ }^{\mathbf{V I}^{\prime}} \mathbf{L}^{\prime}$ in dried and distilled THF, $0.1 \mathrm{M}\left[n-\mathrm{Bu}_{4} \mathrm{~N}\right]\left[\mathrm{BPh}_{4}\right]$ vs. $\mathrm{Fc} / \mathrm{Fc}^{+}$(referenced internally to $\mathrm{CoCp}_{2}{ }_{2}$ then externally to $\mathrm{Fc} / \mathrm{Fc}^{+}{ }^{85}$ ). Reference electrode: Silver wire, counter electrode: platinum mesh, working electrode: glassy carbon.

$\mathrm{M}-\mathbf{U}$ without the equatorial coordinated pyridine has a calculated $\mathrm{E}^{0}$ of $-1.41 \mathrm{~V}$, i.e. the uranyl centre is predicted to be easier to reduce by $0.15 \mathrm{~V}$. However, the same $-1.41 \mathrm{~V} \mathrm{E}^{0}$ was calculated for the THF-solvated couples (M-THFU). A similar case is found for the M-solUL ${ }^{\text {pac }}$ complexes ( ortho-phenylenyl-linked ligand as shown in Chart 1). Their reduction potentials calculated in the range of -1.36 to $-1.48 \mathrm{~V}$ are comparable to the experimentally reported $-1.31 \mathrm{~V}^{29,86,87}$ It is found that the calculated $\mathrm{E}^{0}$ decreases (becomes more negative) from M-pyUL $\mathbf{L}^{\text {pac }}$ to $\mathrm{M}$-pyU, suggesting that the former, containing the $\mathrm{L}^{\text {pac }}$ ligand (short ortho-phenylenyl linker), is more easily reduced than the latter with the L ligand (long anthracenyl linker). This is also consistent with the mononuclear uranium(V) complex of the $\mathrm{L}^{\mathrm{pac}}$ macrocycle being experimentally synthesised. ${ }^{27,37,88}$

The reduction of B-pyU was calculated in a stepwise reaction through the intermediate product, B-py $\mathbf{U}^{\mathbf{V I}-\mathbf{V}}$, with mixed VI and V oxidation states, giving reduction potentials of -1.18 and $-2.49 \mathrm{~V}$ for the first $\left(\mathrm{U}^{\mathrm{VI}} \mathrm{U}^{\mathrm{VI}} / \mathrm{U}^{\mathrm{VI}} \mathrm{U}^{\mathrm{V}}\right)$ and second-electron $\left(\mathrm{U}^{\mathrm{VI}} \mathrm{U}^{\mathrm{V}} / \mathrm{U}^{\mathrm{V}} \mathrm{U}^{\mathrm{V}}\right)$ reduction processes, respectively. These correspond to 
the experimental results of $\mathrm{E}_{1 / 2}=-1.07 \mathrm{~V}\left(\mathrm{U}^{\mathrm{VI}} \mathrm{U}^{\mathrm{VI}} / \mathrm{U}^{\mathrm{VI}} \mathrm{U}^{\mathrm{V}}, \mathrm{E}_{\mathrm{p}}{ }^{\mathrm{c}}=-1.23 \mathrm{~V}\right.$ and $\mathrm{E}_{\mathrm{p}}{ }^{\mathrm{a}}=$ $-0.91 \mathrm{~V})$ and $\mathrm{E}_{1 / 2}=-1.36 \mathrm{~V}\left(\mathrm{U}^{\mathrm{VI}} \mathrm{U}^{\mathrm{V}} / \mathrm{U}^{\mathrm{V}} \mathrm{U}^{\mathrm{V}}, \mathrm{E}_{\mathrm{p}}{ }^{\mathrm{c}}=-1.58 \mathrm{~V}\right.$ and $\left.\mathrm{E}_{\mathrm{p}}{ }^{\mathrm{a}}=-1.14 \mathrm{~V}\right)($ See Figure S6). The large difference of the second-electron reduction potentials between calculation and experiment is attributed to the correction used that did not include all the SOC and multiplet effects. In fact, the SOC correction of $0.31 \mathrm{eV}$ was generated by calculations of mononuclear actinyl complexes. ${ }^{80}$ Regarding the binuclear B-pyU, it is still correct for the first-electron reduction of $\mathrm{U}^{\mathrm{VI}} \mathrm{U}^{\mathrm{VI}} / \mathrm{U}^{\mathrm{VI}} \mathrm{U}^{\mathrm{V}}$ because the unchanged $\mathrm{U}^{\mathrm{VI}}$ ion has negligible SOC effect (See the second row in Table S7). For the second-electron reduction of $\mathrm{U}^{\mathrm{VI}} \mathrm{U}^{\mathrm{V}} / \mathrm{U}^{\mathrm{V}} \mathrm{U}^{\mathrm{V}}$ however, the correction value should be significantly different (the third row of Table S7). First, multiplet effects should be involved for two unpaired electrons. Second, the SOC effects of the unchanged $\mathrm{U}^{\mathrm{V}}$ atom may not be ignored. As a result, a much larger correction value than the $0.31 \mathrm{eV}$ used would give better agreement between computed and measured results.

Across the actinide series considered here, the $\mathrm{E}^{0}$ values follow the sequence of $\mathrm{Np}>\mathrm{Pu}>\mathrm{U}$ for both mono- and binuclear complexes (Figure 5). This agrees with the trend of the experimentally measured reduction potentials of $\left[\left(\mathrm{An}^{\mathrm{VI}} \mathrm{O}_{2}\right)\left(\mathrm{H}_{2} \mathrm{O}\right)_{5}\right]^{2+} /\left[\left(\mathrm{An}^{\mathrm{V}} \mathrm{O}_{2}\right)\left(\mathrm{H}_{2} \mathrm{O}\right)_{5}\right]^{+}(\mathrm{An}=\mathrm{U}, \mathrm{Np}$ and $\mathrm{Pu}){ }^{80,89}$

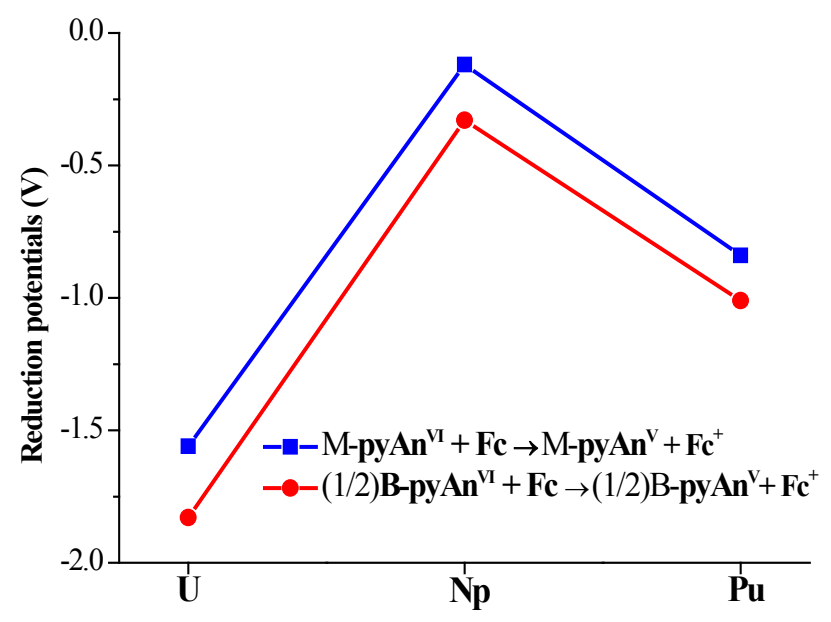

Figure 5. Calculated redox potentials (versus $\mathrm{Fc} / \mathrm{Fc}^{+}$) of single-electron reduction reactions of B-pyAn ${ }^{\mathbf{m}}$ and M-py $\mathbf{A} \mathbf{n}^{\mathbf{m}}(\mathrm{m}=\mathrm{VI}$ and V) in pyridine solution.

\section{Conclusions}


Systematic relativistic DFT studies have been performed on actinide complexes of the stretched, anthracenyl-hinged macrocycle. Detailed comparisons with their pyridine-free analogues and experimentally-synthesised uranium complexes have been made.

It is found that the pyridine solvent that coordinates equatorially to the uranyl(VI) ion must be explicitly included in the structural optimization to achieve good correlation between experimental, X-ray diffraction-determined and computational geometries. On the other hand, the condensed-phase media and the ligand simplification have only a slight effect. The one electron-reduced bis-uranyl(V) complex exhibits a slight additional deviation from co-planarity of the two $\mathrm{N}_{4}$-donor compartments and simultaneously a slight additional lateral twist of the macrocycle. This is attributed to the increased repulsion of the endo-oxo atoms of the two uranyl(V) ions arising from increased Lewis basicity of the oxo groups. Similar structures were obtained for other binuclear transuranium analogues. Regarding the mononuclear complexes, the plutonyl(V) complex has the largest twist angle of the macrocycle, in contrast to the other complexes being theoretically predicted as co-facial "Pacman" structures.

Experimentally, routes to pure bis- or mono-uranyl(VI) complexes have now been developed, using an alternative synthetic route, and the molecular structures of both pyridine and THF-solvated adducts determined. Notably, the mono-uranyl(VI) complex can be accessed cleanly using non-coordinating reaction solvents, whilst quantitative conversion to the bis-uranyl(VI) species requires 2.5 equivalents of $\left[(\mathrm{sol})_{2}\left(\mathrm{UO}_{2}\right)\left(\mathrm{N}\left(\mathrm{SiMe}_{3}\right)_{2}\right)_{2}\right]($ sol = pyridine and THF). The X-ray crystal diffraction data show agreement with the calculated results.

Finally, single-electron reduction potentials of mono- and binuclear complexes in pyridine solution have been calculated at a level that considers both solvation and multiplet/SOC effects, and found to follow the order of $\mathrm{Np}>\mathrm{Pu}>\mathrm{U}$. The $\mathrm{E}^{0}$ value of the $\mathrm{U}^{\mathrm{VI}}$ to $\mathrm{U}^{\mathrm{V}}$ reduction couple for $\mathrm{M}-\mathbf{p y} \mathrm{U}$ was calculated to be $-1.56 \mathrm{~V}$ versus $\mathrm{Fc}^{+} / \mathrm{Fc}$, remarkably close to the experimental value of $-1.57 \mathrm{~V}$. The agreement between calculation $(-1.18 \mathrm{~V})$ and experiment $(-1.07 \mathrm{~V})$, of the $\mathrm{U}^{\mathrm{VI}} \mathrm{U}^{\mathrm{VI}}$ to $\mathrm{U}^{\mathrm{VI}} \mathrm{U}^{\mathrm{V}}$ reduction 
couple for the binuclear complex is good, but poor agreement was found for the second redox process, i.e. the $\mathrm{U}^{\mathrm{VI}} \mathrm{U}^{\mathrm{V}}$ to $\mathrm{U}^{\mathrm{V}} \mathrm{U}^{\mathrm{V}}$ reduction couple. The large difference is attributed to the correction used which neglects the multiplet and/or SOC effects in the $\mathrm{U}^{\mathrm{VI}} \mathrm{U}^{\mathrm{V}} / \mathrm{U}^{\mathrm{V}} \mathrm{U}^{\mathrm{V}}$ reduction process.

The radiotoxicity of neptunyl and plutonyl salts is between thousands and tens of thousands times more than that of uranyl salts, making their synthetic chemistry far from simple, yet the additional f-electrons in their common actinyl cations significantly change their behaviour compared to the $\mathrm{d}^{0} \mathrm{f}^{0}$ uranyl dication. The close agreement between experimental and computational results presented for the mono and bis(uranyl), and neutral and singly reduced uranyl complexes reported here supports our confidence in making computational predictions of the behaviour of the neptunyl and plutonyl analogues, and warn of the greater discrepancies in higher $\mathrm{f}^{\mathrm{n}}$ electron count systems. Work is in progress to reproduce the predicted chemistry for the transuranics.

\section{Acknowledgements}

This work is supported by the National Natural Science Foundation of China (21273063) and the Scientific Foundations of State Education Ministry and Heilongjiang Province for the Returned Overseas Chinese Scholars. GS acknowledges financial support from the Natural Sciences and Engineering Research Council of Canada (NSERC, Discovery Grant). PLA thanks the Technische Universität München - Institute for Advanced Study, funded by the German Excellence Initiative; PLA and JBL thank the University of Edinburgh, and the Engineering and Physical Sciences Research Council EPSRC EP/M010554/1, EP/H004823/1, and EP/G038945/1. The authors are grateful to Dr. Dimitri Laikov for providing us with the Priroda code.

\section{Supporting Information Available}

Table of formulas and abbreviations of the investigated complexes (Table S1); 
tables of calculated and experimental values of the THF-solvated complexes (S2); tables of optimised geometry parameters of B-py $\mathbf{U}$ and B-U in various approaches (S3) and of pyridine-free actinyl complexes (S4 and S5); table of X-ray crystallography parameters (S6); and table of the correction energy of reduction reaction for uranyl complexes (S7). Chart to describe the difference between calculated B-U $\mathbf{U}^{\mathbf{V I}} / \mathbf{B}-\mathbf{p y} \mathbf{U}^{\mathbf{V I}}$ and experimental B-pyU $\mathbf{U}^{\mathrm{VI}} \mathbf{L}^{\prime}$; figures of energetic levels and diagrams of orbitals of $\mathbf{B}-\mathbf{p y} \mathbf{U}^{\mathbf{V I}}$ calculated with various functionals (Figures $\mathrm{S} 1 \sim \mathrm{S} 3$ ); figures of X-ray crystal structures of THF-solvated uranyl(VI) complexes (S4 and S5); and CV plots of B-py $\mathbf{U}^{\mathbf{V I}} \mathbf{L}^{\prime}$ (S6). Computational/Experimental details and full reference of the ADF and Gaussian codes. Crystallographic data in CIF, codes $1430531-1430533$

\section{References}

1. D. L. Clark, D. E. Hobart and M. P. Neu, Chem. Rev., 1995, 95, 25-48.

2. J. M. Hashke and J. L. Stakebake, in The chemistry of the actinide and transactinide elements, eds. L. R. Morss, N. M. Edelstein and J. Fuger, Springer, 2006, ch. 29, pp. 3199-3272.

3. G. R. Choppin, J. Radioanal. Nucl. Chem., 2007, 273, 695-703.

4. G. R. Choppin and M. P. Jensen, in The chemistry of the actinide and transactinide elements, eds. L. R. Morss, N. M. Edelstein and J. Fuger, Springer, 2006, ch. 23, p. 2554.

5. B. M. Rambo and J. L. Sessler, Chem. Eur. J., 2011, 17, 4946-4959.

6. T. W. Hayton, Nat. Chem., 2013, 5, 451-452.

7. R. G. Denning, J. Phys. Chem. A, 2007, 111, 4125-4143.

8. P. L. Arnold, J. B. Love and D. Patel, Coord. Chem. Rev., 2009, 253, 1973-1978.

9. Z. Szabó, T. Toraishi, V. Vallet and I. Grenthe, Coord. Chem. Rev., 2006, 250, 784-815.

10. C. J. Burns, D. L. Clark, R. J. Donohoe, P. B. Duval, B. L. Scott and C. D. Tait, Inorg. Chem., 2000, 39, 5464-5468.

11. J. C. Berthet, M. Nierlich and M. Ephritikhine, Chem. Commun., 2004, 870-871.

12. J. C. Berthet, M. Nierlich and M. Ephritikhine, Chem. Commun., 2003, 1660-1661.

13. J. C. Berthet, M. Nierlich and M. Ephritikhine, Angew. Chem.-Int. Edit., 2003, 42, 1952-1954.

14. J. C. Berthet, M. Nierlich and M. Ephritikhine, Dalton Trans., 2004, 2814-2821.

15. C. Villiers, P. Thuery and M. Ephritikhine, Angew. Chem.-Int. Edit., 2008, 47, 5892-5893.

16. N. W. Alcock, D. J. Flanders and D. Brown, J. Chem. Soc.-Dalton Trans., 1985, 1001-1007.

17. N. W. Alcock, D. J. Flanders, M. Pennington and D. Brown, Acta Crystallogr. Sect. C-Cryst. Struct. Commun., 1988, 44, 247-250.

18. W. J. Oldham, S. M. Oldham, B. L. Scott, K. D. Abney, W. H. Smith and D. A. Costa, Chem. Commun., 2001, 1348-1349.

19. M. P. Wilkerson, C. J. Burns, R. T. Paine and B. L. Scott, Inorg. Chem., 1999, 38, 4156-4158.

20. J. L. Sessler, G. Hemmi, T. D. Mody, T. Murai, A. Burrell and S. W. Young, Accounts Chem. 
Res., 1994, 27, 43-50.

21. J. L. Sessler, A. E. Vivian, D. Seidel, A. K. Burrell, M. Hoehner, T. D. Mody, A. Gebauer, S. J. Weghorn and V. Lynch, Coord. Chem. Rev., 2001, 222, 275-275.

22. J. L. Sessler, P. J. Melfi and G. D. Pantos, Coord. Chem. Rev., 2006, 250, 816-843.

23. J. L. Sessler, D. Seidel, A. E. Vivian, V. Lynch, B. L. Scott and D. W. Keogh, Angew. Chem.-Int. Edit., 2001, 40, 591-594.

24. J. L. Sessler, T. D. Mody, M. T. Dulay, R. Espinoza and V. Lynch, Inorg. Chim. Acta, 1996, 246, 23-30.

25. J. L. Sessler, T. D. Mody and V. Lynch, Inorg. Chem., 1992, 31, 529-531.

26. J. B. Love, Chem. Commun., 2009, 3154-3165.

27. P. L. Arnold, D. Patel, C. Wilson and J. B. Love, Nature, 2008, 451, 315-318.

28. P. L. Arnold, A.-F. Pecharman and J. B. Love, Angew. Chem. Int. Ed., 2011, 50, 9456-9458.

29. P. L. Arnold, E. Hollis, F. J. White, N. Magnani, R. Caciuffo and J. B. Love, Angew. Chem. Int. Ed., 2011, 50, 887-890.

30. P. L. Arnold, A.-F. Pecharman, E. Hollis, A. Yahia, L. Maron, S. Parsons and J. B. Love, Nat. Chem., 2010, 2, 1056-1061.

31. P. L. Arnold, D. Patel, A. J. Blake, C. Wilson and J. B. Love, J. Am. Chem. Soc., 2006, 128, 9610-9611.

32. L. Natrajan, F. Burdet, J. Pecaut and M. Mazzanti, J. Am. Chem. Soc., 2006, 128, 7152-7153.

33. A. E. Vaughn, C. L. Barnes and P. B. Duval, J. Chem. Crystallogr., 2007, 37, 779-782.

34. J. L. Sessler, W. S. Cho, S. P. Dudek, L. Hicks, V. M. Lynch and M. T. Huggins, J. Porphyr. Phthalocyanines, 2003, 7, 97-104.

35. G. Givaja, A. J. Blake, C. Wilson, M. Schroder and J. B. Love, Chem. Commun., 2003, 2508-2509.

36. P. L. Arnold, A. J. Blake, C. Wilson and J. B. Love, Inorg. Chem., 2004, 43, 8206-8208.

37. P. L. Arnold, G. M. Jones, S. O. Odoh, G. Schreckenbach, N. Magnani and J. B. Love, Nat. Chem., 2012, 4, 221-227.

38. P. L. Arnold, G. M. Jones, Q.-J. Pan, G. Schreckenbach and J. B. Love, Dalton Trans., 2012, 41, 6595-6597.

39. Q. J. Pan, G. A. Shamov and G. Schreckenbach, Chem. Eur. J., 2010, 16, 2282-2290.

40. Q. J. Pan and G. Schreckenbach, Inorg. Chem., 2010, 49, 6509-6517.

41. Q. J. Pan, G. Schreckenbach, P. L. Arnold and J. B. Love, Chem. Commun., 2011, 47, 5720-5722.

42. J. C. Sullivan, A. J. Zielen and J. C. Hindman, J. Am. Chem. Soc., 1961, 83, 3373-3378.

43. M. P. Wilkerson, C. J. Burns, H. J. Dewey, J. M. Martin, D. E. Morris, R. T. Paine and B. L. Scott, Inorg. Chem., 2000, 39, 5277-5285.

44. T. A. Sullens, R. A. Jensen, T. Y. Shvareva and T. E. Albrecht-Schmitt, J. Am. Chem. Soc., 2004, 126, 2676-2677.

45. E. V. Alekseev, S. V. Krivovichev, W. Depmeier, O. I. Siidra, K. Knorr, E. V. Suleimanov and E. V. Chuprunov, Angew. Chem.-Int. Edit., 2006, 45, 7233-7235.

46. E. V. Alekseev, S. V. Krivovichev, T. Malcherek and W. Depmeier, Inorg. Chem., 2007, 46, 8442-8444

47. E. V. Alekseev, S. V. Krivovichev, W. Depmeier, T. Armbruster, H. Katzke, E. V. Suleimanov and E. V. Chuprunov, J. Solid State Chem., 2006, 179, 2977-2987. 
48. K. A. Kubatko and P. C. Burns, Inorg. Chem., 2006, 45, 10277-10281.

49. S. D. Reilly and M. P. Neu, Inorg. Chem., 2006, 45, 1839-1846.

50. J. L. Sessler, A. E. V. Gorden, D. Seidel, S. Hannah, V. Lynch, P. L. Gordon, R. J. Donohoe, C. D. Tait and D. W. Keogh, Inorg. Chim. Acta, 2002, 341, 54-70.

51. I. A. Charushnikova, N. N. Krot and I. N. Polyakova, Crystallogr. Rep., 2006, 51, 201-204.

52. A. E. V. Gorden, J. D. Xu, K. N. Raymond and P. Durbin, Chem. Rev., 2003, 103, 4207-4282.

53. M. S. Grigoriev, N. N. Krot, A. A. Bessonov and K. Y. Suponitsky, Acta Crystallogr. Sect. E.-Struct Rep. Online, 2007, 63, M561-M562.

54. S. Nagasaki, K. Kinoshita, Y. Enokida and A. Suzuki, J. Nucl. Sci. Technol., 1992, 29, 1100-1107.

55. F. Burdet, J. Pecaut and M. Mazzanti, J. Am. Chem. Soc., 2006, 128, 16512-16513.

56. D. N. Laikov, J. Comput. Chem., 2007, 28, 698-702.

57. D. N. Laikov and Y. A. Ustynyuk, Russ. Chem. Bull., 2005, 54, 820-826.

58. D. N. Laikov, Chem. Phys. Lett., 2005, 416, 116-120.

59. D. N. Laikov, Ph.D. Thesis, Moscow State University, Moscow, 2000.

60. D. N. Laikov, Chem. Phys. Lett., 1997, 281, 151-156.

61. D. N. Laikov, An Implementation of the Scalar Relativistic Density Functional Theory for Molecular Calculatios with Gaussian Basis Sets, DFT2000 Conference, Menton, France, 2000.

62. K. G. Dyall, J. Chem. Phys., 1994, 100, 2118-2127.

63. J. P. Perdew, K. Burke and M. Ernzerhof, Phys. Rev. Lett., 1996, 77, 3865-3868.

64. I. Mayer, Simple theorems, proof and derivations in quantum chemistry, Kluwer Academic /Plenum Publishers: New York, 2003.

65. G. te Velde, F. M. Bickelhaupt, E. J. Baerends, C. Fonseca Guerra, S. J. A. Van Gisbergen, J. G. Snijders and T. Ziegler, J. Comput. Chem., 2001, 22, 931-967.

66. C. Fonseca Guerra, J. G. Snijders, G. te Velde and E. J. Baerends, Theor. Chem. Acc., 1998, 99, 391-403.

67. E. J. Baerends, T. Ziegler, J. Autschbach and et. al., SCM, Theoretical Chemistry, Vrije Universiteit, Amsterdam, The Netherlands, ADF2010.02 edn., 2010. (see the full reference in $\mathrm{SI})$

68. C. C. Pye and T. Ziegler, Theor. Chem. Acc., 1999, 101, 396-408.

69. A. Klamt and G. Schuurmann, J. Chem. Soc., Perkin Trans., 1993, 799-805.

70. A. Klamt, V. Jonas, T. Burger and J. C. W. Lohrenz, J. Phys. Chem. A, 1998, 102, 5074-5085.

71. G. A. Shamov and G. Schreckenbach, J. Phys. Chem. A, 2006, 110, 9486-9499.

72. Q.-J. Pan, G. Schreckenbach, P. L. Arnold and J. B. Love, Chem. Commun., 2011, 47, 5720-5722.

73. E. van Lenthe, A. Ehlers and E. J. Baerends, J. Chem. Phys., 1999, 110, 8943-8953.

74. E. van Lenthe, E. J. Baerends and J. G. Snijders, J. Chem. Phys., 1994, 101, 9783-9792.

75. E. van Lenthe, E. J. Baerends and J. G. Snijders, J. Chem. Phys., 1993, 99, 4597-4610.

76. E. van Lenthe, J. Snijders and E. Baerends, J. Chem. Phys., 1996, 105, 6505-6516.

77. M. J. Frisch, G. W. Trucks, H. B. Schlegel and e. al., Gaussian, Inc., Wallingford CT, Gaussian 09, Revision D.01 edn., 2009. (see the full reference in SI)

78. G. A. Shamov, G. Schreckenbach and T. N. Vo, Chem. Eur. J., 2007, 13, 4932-4947.

79. G. A. Shamov and G. Schreckenbach, J. Phys. Chem. A, 2005, 109, 10961-10974. 
80. P. J. Hay, R. L. Martin and G. Schreckenbach, J. Phys. Chem. A, 2000, 104, 6259-6270.

81. H. Steele and R. J. Taylor, Inorg. Chem., 2007, 46, 6311-6318.

82. L. Gagliardi and B. O. Roos, Chem. Soc. Rev., 2007, 36, 893-903.

83. G. Nocton, P. Horeglad, V. Vetere, J. Pécaut, L. Dubois, P. Maldivi, N. M. Edelstein and M. Mazzanti, J. Am. Chem. Soc., 2009, 132, 495-508.

84. J. L. Brown, G. Wu and T. W. Hayton, J. Am. Chem. Soc., 2010, 132, 7248-7249.

85. J. R. Aranzaes, M.-C. Daniel and D. Astruc, Canadian Journal of Chemistry, 2006, 84, 288-299.

86. N. G. Connelly and W. E. Geiger, Chem. Rev., 1996, 96, 877-910.

87. D. Chang, T. Malinski, A. Ulman and K. M. Kadish, Inorg. Chem., 1984, 23, 817-824.

88. G. M. Jones, P. L. Arnold and J. B. Love, Chem. Eur. J., 2013, 19, 10287-10294.

89. J. R. Brand and J. W. Cobble, Inorg. Chem., 1970, 9, 912-917. 
Table 1. Optimised global geometry parameters ${ }^{[a]}$ of binuclear and mononuclear actinyl complexes, compared with experimental values of the uranyl(VI) complex ${ }^{[b]}$. (Angles in degree and distances in $\AA$ )

\begin{tabular}{|c|c|c|c|c|c|c|c|c|}
\hline & Approach ${ }^{[c]}$ & $\alpha$ & $\beta$ & $\theta(\mathrm{f})$ & $\theta(\mathrm{s})$ & $\mathrm{D}$ & $\mathrm{U} \cdots \mathrm{U}$ & $\mathrm{O}_{\text {endo }} \cdots \mathrm{O}_{\text {endo }}$ \\
\hline B-pyU $\mathbf{U}^{\mathbf{V I}}$ & A1 & 17.0 & 13.2 & 177.4 & 174.5 & 7.189 & 5.934 & 2.786 \\
\hline B-py $\mathbf{U}^{\mathrm{VI}}$ & $\mathrm{A} 2$ & 12.1 & 11.1 & 177.7 & 166.2 & 7.546 & 5.896 & 2.753 \\
\hline B-py $\mathbf{U}^{\mathrm{VI}}$ & A3 & 13.3 & 11.0 & 178.0 & 167.6 & 7.621 & 5.921 & 2.735 \\
\hline $\mathrm{B}-\mathbf{U}^{\mathbf{V I}}$ & A1 & 40.5 & 38.4 & 172.5 & 123.5 & 4.262 & 5.106 & 2.940 \\
\hline $\mathrm{B}-\mathbf{U}^{\mathbf{V I}}$ & A2 & 34.9 & 36.3 & 174.7 & 130.5 & 5.059 & 5.175 & 2.880 \\
\hline $\mathrm{B}-\mathbf{U}^{\mathbf{V I}}$ & A3 & 35.9 & 37.1 & 173.3 & 129.7 & 4.833 & 5.144 & 2.886 \\
\hline B-py $\mathbf{U}^{\mathrm{VI}} \mathbf{L}^{\prime}$ & $\mathrm{A} 1$ & 23.1 & 17.9 & 177.1 & 171.2 & 7.366 & 5.890 & 2.768 \\
\hline B-pyU $\mathbf{U}^{\mathbf{V I}} \mathbf{L}^{\prime}$ & Expt. & 16.8 & 22.6 & 177.3 & 172.9 & 6.819 & 5.699 & 2.708 \\
\hline B-pyNp & A1 & 17.3 & 17.0 & 177.8 & 176.1 & 7.329 & 5.821 & 2.742 \\
\hline B-pyPu & A1 & 18.7 & 15.6 & 177.2 & 177.0 & 7.381 & 5.975 & 2.811 \\
\hline B-py $\mathbf{U}^{\mathbf{v}}$ & A1 & 34.2 & 21.1 & 178.3 & 162.9 & 7.523 & 6.223 & 2.937 \\
\hline B-pyNp ${ }^{v}$ & A1 & 38.8 & 23.7 & 177.8 & 157.8 & 7.547 & 6.194 & 3.001 \\
\hline B-pyPu ${ }^{v}$ & A1 & 39.2 & 25.6 & 177.9 & 157.8 & 7.498 & 6.242 & 3.068 \\
\hline M-pyU $\mathbf{U I}^{\mathrm{VI}}$ & A1 & 11.0 & 4.8 & & & 7.791 & & \\
\hline M-py $\mathbf{U}^{\mathrm{VI}} \mathbf{L}^{\prime}$ & A1 & 19.6 & 5.2 & & & 7.649 & & \\
\hline M-py $\mathbf{U}^{\mathrm{VI}^{\prime}} \mathbf{L}^{\prime}$ & Expt. & 22.2 & 12.9 & & & 7.189 & & \\
\hline M-pyNp & A1 & 11.2 & 4.2 & & & 7.760 & & \\
\hline M-pyPu & A1 & 9.9 & 5.7 & & & 7.869 & & \\
\hline M-py $\mathbf{U}^{\mathbf{V}}$ & A1 & 9.2 & 6.8 & & & 8.128 & & \\
\hline M-pyNp v & A1 & 7.9 & 6.6 & & & 8.235 & & \\
\hline M-pyPu & $\mathrm{A} 1$ & 12.1 & 22.7 & & & 7.764 & & \\
\hline
\end{tabular}

[a] The definitions of bite angle ( $\alpha$ ), twist angle ( $\beta)$, angles between two actinyl rods $(\theta(\mathrm{f})$ and $\theta(\mathrm{s}))$, as well as normal distance (D) are shown in Chart 3.

${ }^{[b]}$ The experimental complexes, B-py $\mathbf{U}^{\mathbf{V I}} \mathbf{L}^{\prime}$ and $\mathbf{M}-\mathbf{p y} \mathbf{U}^{\mathrm{VI}} \mathbf{L}^{\prime}$, were structurally characterised in the present work, where the binuclear one was reported previously. ${ }^{38}$

[c] Three theoretical approaches, A1, A2 and A3, were used in calculations, corresponding to Priroda: PBE/B-I/AE/gas, ADF: PBE/B-II/ZORA/gas and ADF: PBE/B-II/ZORA/COSMO, respectively. 
Table 2. Optimised geometry parameters and bond orders (in parentheses) for binuclear actinyl complexes in the gas phase, compared with experimental values of the uranyl(VI) complex. (Bond lengths in $\AA$ and angles in degree)

\begin{tabular}{|c|c|c|c|c|c|c|c|c|}
\hline & B-py $\mathbf{U}^{\mathrm{VI}}$ & B-py $\mathbf{U}^{\mathrm{VI}} \mathbf{L}^{\prime}$ & B-py $\mathbf{U}^{\mathrm{VI}} \mathbf{L}^{\prime}$ & B-py $\mathbf{U}^{\mathbf{V}}$ & B-pyNp ${ }^{V I}$ & B-pyNp ${ }^{v}$ & B-pyPu ${ }^{\text {VI }}$ & B-pyPu ${ }^{v}$ \\
\hline & Cal. & Cal. & Expt. ${ }^{[a]}$ & Cal. & Cal. & Cal. & Cal. & Cal. \\
\hline \multirow[t]{2}{*}{$\mathrm{An}_{1}-\mathrm{O}_{\mathrm{exo}}$} & 1.811 & 1.811 & $1.777(4)$ & 1.838 & 1.791 & 1.829 & 1.790 & 1.824 \\
\hline & $(2.37)$ & $(2.37)$ & & $(2.35)$ & $(2.35)$ & $(2.34)$ & $(2.32)$ & $(2.32)$ \\
\hline \multirow[t]{2}{*}{$\mathrm{An}_{2}-\mathrm{O}_{\text {exo }}$} & 1.810 & 1.809 & $1.779(4)$ & 1.838 & 1.792 & 1.829 & 1.789 & 1.824 \\
\hline & $(2.37)$ & $(2.37)$ & & $(2.35)$ & $(2.35)$ & $(2.34)$ & (2.32) & $(2.31)$ \\
\hline \multirow{2}{*}{$\mathrm{An}_{1}-\mathrm{O}_{\text {endo }}$} & 1.793 & 1.793 & $1.764(4)$ & 1.812 & 1.782 & 1.806 & 1.782 & 1.797 \\
\hline & $(2.39)$ & (2.39) & & $(2.38)$ & $(2.37)$ & $(2.36)$ & $(2.32)$ & $(2.35)$ \\
\hline \multirow[t]{2}{*}{$\mathrm{An}_{2}-\mathrm{O}_{\text {endo }}$} & 1.801 & 1.799 & $1.747(4)$ & 1.812 & 1.775 & 1.806 & 1.772 & 1.797 \\
\hline & $(2.37)$ & $(2.37)$ & & $(2.38)$ & $(2.38)$ & $(2.36)$ & $(2.35)$ & $(2.35)$ \\
\hline \multirow[t]{2}{*}{$\mathrm{An}_{1}-\mathrm{N}_{\mathrm{py} 1}$} & 2.628 & 2.631 & $2.567(5)$ & 2.564 & 2.639 & 2.613 & 2.661 & 2.645 \\
\hline & $(0.35)$ & $(0.35)$ & & $(0.45)$ & $(0.33)$ & $(0.37)$ & $(0.30)$ & $(0.30)$ \\
\hline \multirow[t]{2}{*}{$\mathrm{An}_{2}-\mathrm{N}_{\mathrm{py} 2}$} & 2.653 & 2.663 & $2.611(6)$ & 2.564 & 2.611 & 2.613 & 2.621 & 2.656 \\
\hline & $(0.34)$ & $(0.34)$ & & $(0.45)$ & $(0.34)$ & $(0.37)$ & $(0.32)$ & $(0.30)$ \\
\hline $\mathrm{O}-\mathrm{An}_{1}-\mathrm{O}$ & 170.5 & 174.6 & 174.0 & 175.0 & 175.2 & 176.1 & 177.5 & 176.8 \\
\hline $\mathrm{O}-\mathrm{An}_{2}-\mathrm{O}$ & 174.3 & 171.2 & 176.0 & 175.0 & 177.5 & 176.2 & 177.9 & 176.8 \\
\hline
\end{tabular}

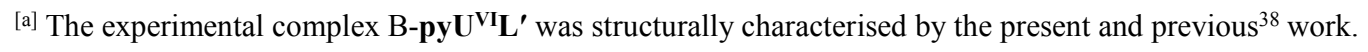


Table 3. Optimised geometry parameters and bond orders (in parentheses) for mononuclear actinyl complexes in the gas phase, together with experimental values of the uranyl(VI) complex. (Bond lengths in $\AA$ and angles in degree)

\begin{tabular}{|c|c|c|c|c|c|c|c|c|}
\hline & M-pyU VI & M-py $\mathbf{U}^{\mathrm{VI}} \mathbf{L}^{\prime}$ & 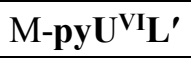 & M-py $\mathbf{U}^{\mathbf{V}}$ & M-pyNp & M-pyNpv & M-pyPu ${ }^{\text {VI }}$ & M-pyPu \\
\hline & Cal. & Cal. & Expt. & Cal. & Cal. & Cal. & Cal. & Cal. \\
\hline \multirow[t]{2}{*}{ An- $\mathrm{O}_{\text {exo }}$} & 1.807 & 1.808 & $1.768(2)$ & 1.830 & 1.790 & 1.825 & 1.788 & 1.815 \\
\hline & $(2.38)$ & $(2.38)$ & & $(2.37)$ & $(2.37)$ & $(2.36)$ & $(2.34)$ & $(2.34)$ \\
\hline \multirow[t]{2}{*}{ An- $\mathrm{O}_{\text {endo }}$} & 1.818 & 1.817 & $1.780(2)$ & 1.842 & 1.801 & 1.837 & 1.794 & 1.843 \\
\hline & $(2.34)$ & $(2.35)$ & & $(2.33)$ & $(2.33)$ & $(2.31)$ & $(2.31)$ & $(2.31)$ \\
\hline \multirow{2}{*}{$A n-N_{p y}$} & 2.618 & 2.613 & $2.565(3)$ & 2.572 & 2.602 & 2.613 & 2.614 & 2.657 \\
\hline & $(0.37)$ & $(0.37)$ & & $(0.42)$ & $(0.36)$ & $(0.35)$ & $(0.34)$ & $(0.34)$ \\
\hline $\mathrm{O}_{\text {endo }} \cdots \mathrm{H}_{1}(\mathrm{~N})$ & 3.222 & 3.216 & 3.989 & 3.161 & 3.134 & 3.320 & 3.217 & 3.664 \\
\hline $\mathrm{O}_{\text {endo }} \cdots \mathrm{H}_{2}(\mathrm{~N})$ & 3.028 & 3.265 & 2.802 & 3.128 & 3.137 & 2.947 & 3.187 & 2.148 \\
\hline $\mathrm{O}_{\text {endo }} \cdots \mathrm{H}_{3}(\mathrm{C})$ & 2.463 & 2.552 & 2.654 & 2.387 & 2.450 & 2.365 & 2.490 & 2.378 \\
\hline $\mathrm{O}-\mathrm{An}-\mathrm{O}$ & 173.7 & 173.7 & 175.1 & 174.7 & 177.0 & 176.0 & 177.2 & 177.0 \\
\hline
\end{tabular}


Table 4. Calculated energies $(\mathrm{eV})$ of single-electron reduction reactions of binuclear and mononuclear actinyl complexes, together with redox potential $\mathrm{E}^{0}\left(\mathrm{~V}\right.$, versus $\left.\mathrm{Fc}^{+} / \mathrm{Fc}\right)$ and available experimental values.

\begin{tabular}{|c|c|c|c|c|c|c|c|c|}
\hline Reduction Reactions & An & $\Delta_{\mathrm{r}} \mathrm{E}($ gas $)$ & $\Delta_{\mathrm{r}} \mathrm{E}_{0}(\mathrm{gas})$ & $\Delta_{\mathrm{r}} \mathrm{G}($ gas $)$ & $\Delta_{\mathrm{r}} \mathrm{G}(\mathrm{sol})$ & $\mathrm{E}^{0[\mathrm{a}]}$ & $\mathrm{E}_{\text {corr }}^{0}{ }^{[\mathrm{b}]}$ & $\mathrm{E}_{1 / 2}\left(\mathrm{E}_{\mathrm{p}}^{\mathrm{c}} / \mathrm{E}_{\mathrm{p}}^{\mathrm{a}}\right)$ (Expt.) \\
\hline \multirow[t]{3}{*}{ M-pyAn ${ }^{\mathrm{VI} \rightarrow \mathbf{V}}$} & $\mathrm{U}$ & -1.92 & -2.01 & -1.97 & -3.34 & -1.87 & -1.56 & $-1.57(-1.72 /-1.42)^{[\mathrm{c}]}$ \\
\hline & $\mathrm{Np}$ & -2.37 & -2.45 & -2.48 & -3.92 & -1.29 & -0.12 & \\
\hline & $\mathrm{Pu}$ & -2.72 & -2.77 & -2.74 & -4.16 & -1.05 & -0.84 & \\
\hline \multirow[t]{3}{*}{$(1 / 2) B-p y A n^{V I-V I \rightarrow V-V}$} & $\mathrm{U}$ & -0.81 & -0.91 & -0.92 & -3.07 & -2.14 & -1.83 & \\
\hline & $\mathrm{Np}$ & -1.30 & -1.38 & -1.40 & -3.71 & -1.50 & -0.33 & \\
\hline & $\mathrm{Pu}$ & -1.58 & -1.64 & -1.68 & -3.99 & -1.22 & -1.01 & \\
\hline 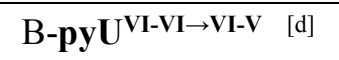 & $\mathrm{U}$ & -2.13 & -2.22 & -2.23 & -3.72 & -1.49 & -1.18 & $-1.07(-1.23 /-0.91)^{[\mathrm{c}]}$ \\
\hline B-py $\mathbf{U}^{\mathrm{VI}-\mathrm{V} \rightarrow \mathbf{V - V}} \quad[\mathrm{d}]$ & $\mathrm{U}$ & 0.52 & 0.40 & 0.39 & -2.41 & -2.80 & -2.49 & $-1.36(-1.58 /-1.14)^{[c]}$ \\
\hline $\mathbf{M}-\mathbf{U}^{\mathbf{V I} \rightarrow \mathbf{V}} \quad[\mathrm{e}]$ & $\mathrm{U}$ & -2.06 & -2.13 & -2.13 & -3.49 & -1.72 & -1.41 & \\
\hline M-THFU $\mathbf{U I}^{\mathrm{VI} \rightarrow \mathbf{V}} \quad[\mathrm{e}]$ & $\mathrm{U}$ & -1.89 & -1.99 & -2.01 & -3.49 & -1.72 & -1.41 & \\
\hline $\mathbf{M}-\mathbf{U}^{\mathrm{VI} \rightarrow \mathbf{V}} \mathbf{L}^{\mathbf{p a c}} \quad[\mathrm{e}]$ & $\mathrm{U}$ & -1.93 & -2.00 & -2.06 & -3.54 & -1.67 & -1.36 & \\
\hline $\mathbf{M}-\mathbf{p y} \mathbf{U}^{\mathrm{VI} \rightarrow \mathbf{V}} \mathbf{L}^{\mathbf{p a c}}[\mathrm{e}]$ & $\mathrm{U}$ & -1.82 & -1.92 & -1.90 & -3.42 & -1.79 & -1.48 & $-1.31^{[\mathrm{f}]}$ \\
\hline$\underset{[\mathrm{e}]}{\mathbf{M}-\mathbf{T H F U}} \mathbf{U}^{\mathrm{VI} \rightarrow \mathbf{V}^{\mathbf{p a c}}}$ & $\mathrm{U}$ & -1.72 & -1.82 & -1.85 & -3.52 & -1.69 & -1.38 & \\
\hline
\end{tabular}

[a] The free energy of $\mathrm{Fc}^{+} / \mathrm{Fc}\left(\Delta_{\mathrm{r}} \mathrm{G}(\mathrm{sol})\right)$ in pyridine solution was calculated to be $-5.21 \mathrm{eV}$.

${ }^{[b]}$ From Ref. ${ }^{80}$; the multiplet and spin-orbit corrections ("Hay corrections") for U, Np and Pu are 0.31, 1.17, 0.21 $\mathrm{eV}$, respectively.

${ }^{[c]}$ Experimental redox potentials of $\mathbf{M}-\mathbf{p y} \mathbf{U}^{\mathrm{VI}^{\prime}} \mathbf{L}^{\prime}$ and B-pyU $\mathbf{U}^{\mathrm{VI}} \mathbf{L}^{\prime}$ reported as reductions were pseudo-reversible, i.e. $\mathrm{E}_{1 / 2}$ (half-wave potential), $\mathrm{E}_{\mathrm{p}}{ }^{\mathrm{c}}$ (cathode potential) and $\mathrm{E}_{\mathrm{p}}{ }^{\mathrm{a}}$ (anode potential). Notably, approximate $\mathrm{E}_{1 / 2}$, being not a valid descriptor for non-reversible reductions, is conveniently to compare with calculated values. See SI for experimental details.

${ }^{[d]}$ A mixed U(VI)-U(V) complex, $\left[(p y)_{2}\left(\mathrm{U}^{\mathrm{VI}} \mathrm{O}_{2}\right)\left(\mathrm{U}^{\mathrm{V}} \mathrm{O}_{2}\right)(\mathrm{L})\right]^{-}\left(\mathrm{B}-\right.$ py $\left.\mathrm{U}^{\mathrm{VI}-\mathrm{V}}\right)$, was optimised using the same approach.

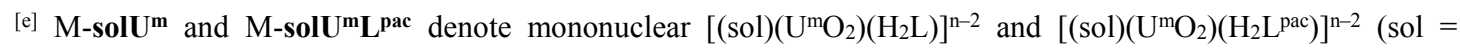
vacant, py, and THF; $m=V I, n=2$; and $m=V, n=1$ ), respectively. $L^{p a c}$ has the ortho-phenylenyl linkers, instead of the anthracenyl linkers in L, see Chart 1.

[f] The experimental single-electron reduction potential was determined at $-0.54 \mathrm{~V}$ (vs. NHE) in pyridine solution, ${ }^{29}$ and the one vs. $\mathrm{Fc}^{+} / \mathrm{Fc}$ was obtained by subtracting $0.77 \mathrm{~V}{ }^{86,87}$ 


\section{Graphical Abstract}

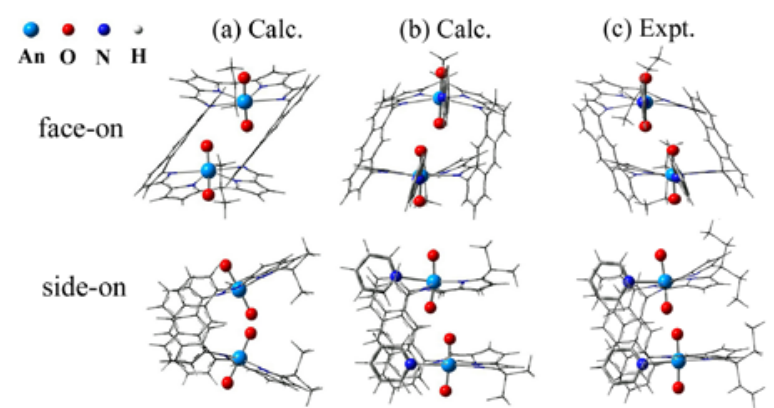

Relativistic DFT calculations present accurate geometries of complexes and redox properties, confirmed by the newly-developed experimental synthesis. 